\title{
SOCIAL NETWORK ANALYSIS OF CLIMATE CHANGE DISCUSSION ON TWITTER
} DURING COP21

$$
\text { by }
$$

Brittany E. Harris, BJ, Ryerson University, 2013

\author{
A thesis presented to Ryerson University \\ in partial fulfillment of the requirements for the degree of \\ Master of Applied Science in the Program of \\ Environmental Applied Science and Management
}

Toronto, Ontario, Canada, 2017

(C) Brittany Harris 2017 


\section{AUTHOR'S DECLARATION}

I hereby declare that I am the sole author of this thesis. This is a true copy of the thesis, including any required final revisions, as accepted by my examiners.

I authorize Ryerson University to lend this thesis to other institutions or individuals for the purpose of scholarly research.

I further authorize Ryerson University to reproduce this thesis by photocopying or by other means, in total or in part, at the request of other institutions or individuals for the purpose of scholarly research.

I understand that my thesis may be made electronically available to the public. 


\title{
SOCIAL NETWORK ANALYSIS OF CLIMATE CHANGE DISCUSSION ON TWITTER DURING COP21
}

\author{
Brittany Elizabeth Harris \\ Master of Applied Science, 2017 \\ Environmental Applied Science and Management \\ Ryerson University
}

\begin{abstract}
The public is increasingly relying on Twitter for climate change information; however, to date, this social media platform is poorly understood in terms of how climate change information is shared. This study evaluates discussions on Twitter during the 2015 United Nations Conference on Climate Change (COP21) to elucidate the social media platform's role in communicating climate change information. For a five-day period, links embedded in a sample of tweets containing "\#climatechange" were characterized, Twitter users were classified by the types of links they typically shared, and their degree centralities (the number of connections for each user) were measured. There was little skeptical content across all user categories; however, news links were more likely than non-news to contain content that is skeptical of climate change. Users who typically shared skeptical news links and users who typically shared non-skeptical non-news links exhibited a relatively high number of connections with other users.
\end{abstract}




\section{ACKNOWLEDGMENTS}

I would first like to thank my supervisor, Dr. Michal Bardecki. Thank you for convincing me that I could successfully complete a graduate degree in science even though my background was in journalism. I appreciate that you allowed me to make this thesis my own but always guided me in the right direction.

I would also like to thank Anatoliy Gruzd and Brittany White for enthusiastically answering my many questions about completing a social network analysis and Netlytic.

I want to express my profound gratitude for my friends and family who have supported me throughout my years of study. Thank you to my parents and sister, my best friends Kristen and Lillianne, and my new friends at Ryerson, Sharmilla, Sarah, and Caitlin. Thank you for bringing me joy, building my confidence, and lending your ear when I needed it most. I would not be here without you.

Finally, I would like to thank my husband for his unwavering support and unconditional love. I cannot possibly thank you enough for everything you have done. Thank you for your positivity, your motivating spirit, and your belief in me. I love you. 


\section{TABLE OF CONTENTS}

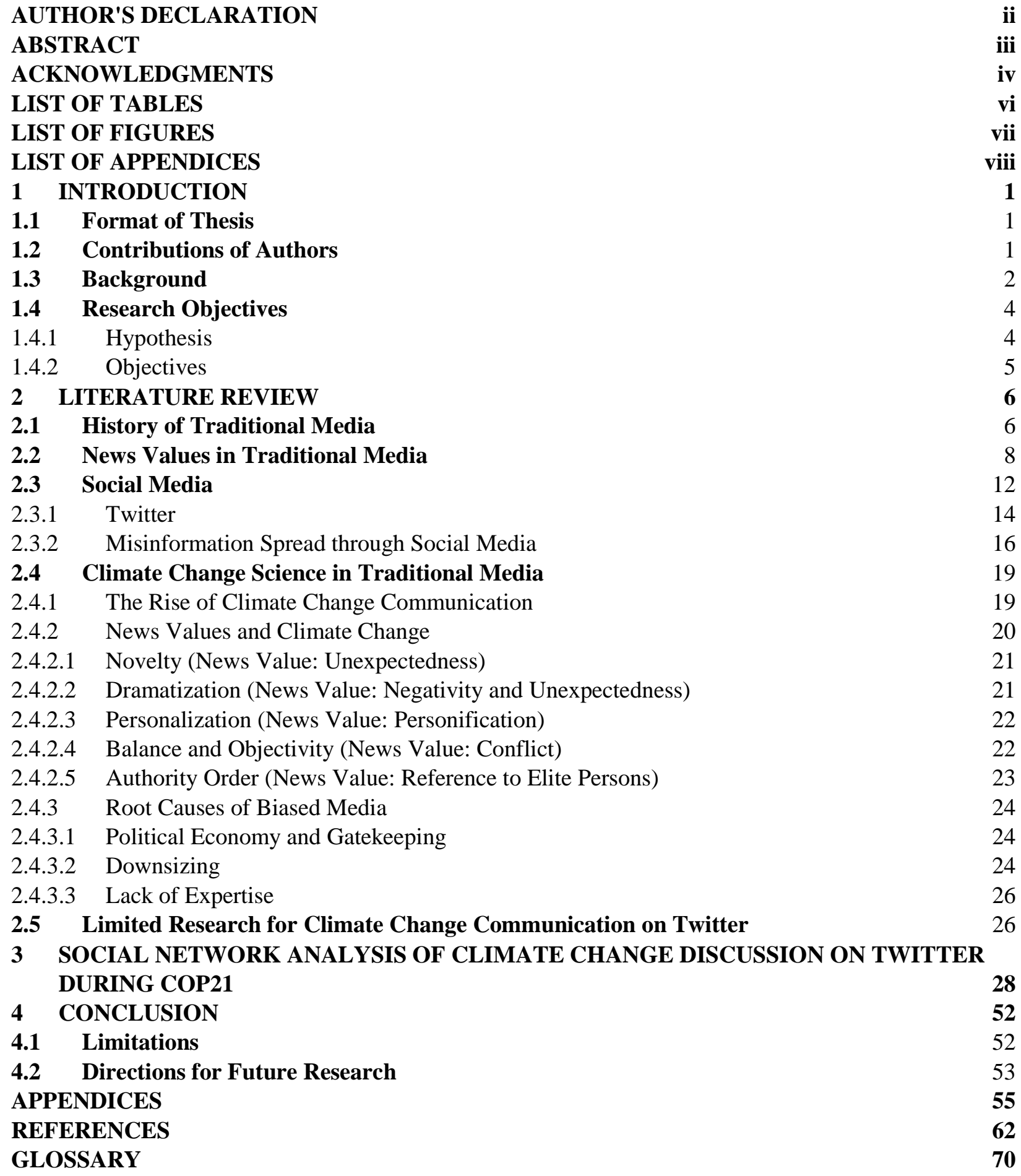




\section{LIST OF TABLES}

Table 1: Traditional and social media terms, definitions, and examples ...................70

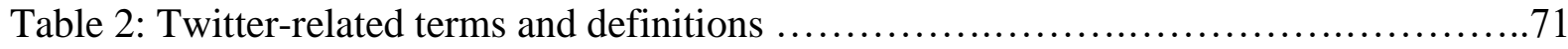




\section{LIST OF FIGURES}

Figure 1: Skeptical/non-skeptical summary of all news and non-news links in sample...44

Figure 2: Degree centrality for news and non-news user categories..................45

Figure 3: Degree centrality for skeptical and non-skeptical user categories.............47

Figure 4: Degree centrality for each user category for top ten users..................49 


\section{LIST OF APPENDICES}

Appendix A: Coding instructions.........................................55

Appendix B: Pew list of top 50 digital news entities.............................60

Appendix C: Intercoder analysis ............................................61 


\section{Introduction}

\subsection{Format of Thesis}

This thesis is presented in a manuscript-based format. Specifically, Chapter Three is a stand-alone paper that is for submission for peer-review and publication in the Journal of Communication. This chapter includes its own introduction, literature review, methods, results, and discussion. It is important to note that because Chapter Three is a stand-alone paper, presented after a comprehensive literature review in Chapter Two, there will be some repetition across Chapters. Chapter Four concludes the thesis with limitations and suggestions for future research.

\subsection{Contributions of Authors}

Manuscript in Chapter Three

Author: Brittany Harris

Contributions: Conceived and implemented the study design. Collected and analyzed data. Prepared manuscript.

Co-Author: Dr. Michal Bardecki

Contributions: Assisted with intercoder reliability. Provided feedback on analysis and manuscript. 


\subsection{Background}

Climate change has devastating implications for food and water supplies, energy production and use, ecosystem and species survival, human health, and social and political stability (IPCC, 2014; Stamm et al., 2000). It is a challenging policy dilemma that requires international cooperation of unprecedented complexity (Lorenzoni et al., 2007; Rice et al., 2015). The situation is exacerbated by the fact that the majority of the public does not understand climate change science nor believe that climate change is a priority (Leiserowitz et al., 2010; Pew Research Center, 2016; Shuckburgh, et al. 2012).

Gallup polls conducted in 2007 and 2008 measured climate change awareness in 127 countries and found that $40 \%$ of adults worldwide had never heard of climate change; this rose to more than $65 \%$ in some developing countries, such as Egypt, Bangladesh, and India (Pelham, 2009). In North America, Europe, and Japan, many citizens have been found to misunderstand climate change and underestimate its importance. For instance, a 2010 study graded the American public's knowledge and understanding of climate change by conducting a survey regarding the climate system and the causes, impacts, and potential solutions to climate change. This study found that $52 \%$ received an $\mathrm{F}(<60 \%$ correct) and only $1 \%$ received an A $(>89 \%$ correct) (Leiserowitz et al., 2010). Other studies have found that less than half of the public in the U.S. believe climate change is caused by anthropogenic forces (Jones et al., 2014; Weber \& Stern, 2011). For example, a Pew Research Center poll (2009) of a U.S. representative sample found that while $84 \%$ of scientists said the earth was getting warmer because of human activity such as burning fossil fuels, just $49 \%$ of non-scientists held this view (Weber \& Stern, 2011). In addition, Jones et al. (2014) found that only four out of ten Americans believe that there is significant consensus amongst scientists regarding global warming. Similar confusion about 
climate change science has been recorded in the United Kingdom. A 2011 survey looking at the public's perception of climate change in the UK, found that many people feel uneducated about, or uninterested in, the findings of climate science, with only $41 \%$ of respondents reporting that they feel they know a fair amount or a lot about climate change (Shuckburgh, et al. 2012). In addition, this survey found that one-third of respondents do not trust climate scientists to tell the truth about climate change and almost half of the respondents believe that the seriousness of climate change is exaggerated (Shuckburgh, et al. 2012). In another survey, conducted in 2004, only $30 \%$ of the British respondents correctly named carbon dioxide as the main gas contributing to climate change (Norton and Leaman, 2004).

A survey conducted by Pew Research Center (2016) found that citizens of countries with high levels of carbon emissions expressed less concern regarding climate change. American and Chinese citizens, whose countries have the highest overall carbon dioxide emissions, are among the least concerned about climate change. The survey found that only $18 \%$ of Chinese and $45 \%$ of Americans think climate change is a very serious problem, and the global median is a mere 54\% (Pew Research Center, 2016). In a 2000 Gallup poll, the environment was ranked sixteenth on American's list of the most important issue facing the country; furthermore, global warming was ranked twelfth out of thirteen environmental issues (Dunlap \& Saad, 2001). Another study in 2014 found that only 5\% of the Americans surveyed considered climate change the most important problem facing the country; when asked which environmental issue is the highest of concern, only one-quarter said climate change (Jones et al., 2014).

These findings are troubling because the leading international body for the assessment of climate change, the Intergovernmental Panel on Climate Change (IPCC), has demonstrated 
that climate change is occurring for anthropogenic reasons and people are currently and will continue to suffer globally from negative effects (IPCC, 2014).

The news media is the largest source of climate change information for the public; however, due to ownership influence, retrenchment, and lack of expertise, the media often resorts to a number of journalistic "news values" that can misconstrue climate change science (Rice et al., 2015; Stamm et al., 2000). The media's representation of climate change has left the public with a flawed understanding of the current situation (Leiserowitz et al., 2010).

The public is increasingly turning to social media (see Glossary for terms and definitions) to get climate change information; however, to date, social media platforms are poorly understood in terms of how climate change information is shared.

The purpose of the present research is to elucidate the role of social media in communicating climate change knowledge and, in particular, to study how certain types of users impact the availability and quality of this knowledge. Specifically, climate change discussions were monitored on Twitter during the 2015 United Nations Conference on Climate Change, which was the 21st session of the Conference of Parties (COP21).

\subsection{Research Objectives}

\subsubsection{Hypothesis}

News links shared on Twitter are more likely to contain skeptical content than links to non-news sources because journalists rely on the news value balance. Users who post these news links will be retweeted more frequently than users who post non-news links because the public has traditionally relied more heavily on news sources for climate change information. 


\subsubsection{Objectives}

To test the aforementioned hypothesis, the following objectives were pursued:

1. To characterize tweets as news or non-news, skeptical or non-skeptical, and original or retweet

2. To measure the proportion of skepticism in news vs. non-news links

3. To classify users into groups based on the types of links that they predominantly share and measure the mean degree centrality of each classification

4. To perform statistical tests to measure whether there are any differences in the mean degree centralities between the various groups 


\section{$2 \quad$ Literature Review}

\subsection{History of Traditional Media}

News originated in the development of oral communities thousands of years ago, but communicating new information over vast expanses of time and space became much easier with the advent of writing (Allan, 2010). It was not until the 18th century, however, that a newspaper was regularly published in Britain and America. By 1750, Britain had five daily papers and by 1783 America had its first daily (Pennsylvania Evening Post and the Daily Advertiser both founded in Philadelphia) (Allan, 2010). This development increased the speed in which people received both local and international information and deepened the breadth of knowledge available.

The invention of the telegraph further increased the speed and expanded the range of communication. The first ever commercial electric telegraph was installed in 1838 on the Great Western Railway, spanning 21 km (Huurderman, 2003). This novel technology freed communication from the limitations of human and animal message systems (Downey, 2013). The telegraph went through a number of advancements up until the development of wireless telegraphy, more commonly known as radio.

In 1920, Westinghouse launched the first commercial radio station, KDKA, in Pittsburgh (Stephens, 2007). By the end of 1922, 576 radio stations were in operation in the U.S., while France did not establish its first radio station until 1923. By 1925, 5.5 million radio sets were in use in America (Stephens, 2007). Radio journalism established itself by emulating the techniques of newspaper journalism. Radio news began to really prove itself as a valuable journalism source in the U.S. when Pearl Harbour was attacked on Dec. 7, 1941 - a Sunday. There were no evening 
papers on Sunday so the event was a radio exclusive from the first bulletin until Monday morning (Stephens, 2007).

After radio, film and television were developed. In the early 20th century, newsreels would play before feature films in theaters. These newsreels eventually led to news being broadcasted on television in individual homes. In 1929, the British Broadcasting Corporation (BBC) started transmitting experimental television pictures; however, the debut of $B B C$ TV news was not until 1948 (BBC, 2016). By 1941, CBS was broadcasting two 15-minute newscasts daily to a tiny audience in New York (Stephens, 2007). At first, this medium just comprised of talking heads with little to no additional visuals. However, by the 1960s the power of TV news was realized as more influential stories were covered, such as Richard Nixon losing to John Kennedy and the shooting of Lee Harvey Oswald (Stephens, 2007). The development of TV news capped centuries of improvements in the means of news dissemination, but even more transformative has been the Internet and the rise of digital news.

The Internet has been said to be as disruptive to today's newspapers as Gutenberg's invention of movable type was to the town criers of the 15th century (Meyer, 2008) and has been described as a 10.5 on the Richter scale of social change (Negroponte, 1996). A massive online migration of media began in the 1990s (Nguyen, 2008) which has impacted media institutions, journalism, political communication, advertising, public relations, communities, and individual social and cultural capital (Macnamara, 2010). This transition has shifted the way news is produced, packaged, distributed, retrieved, and used and provides a diverse range of opportunities thanks to its 24/7 updates, unlimited storage, hypertextuality, searchability, multimedia, customisation, and interactivity (Nguyen, 2008). 
The spread and influence of digital news continues to grow. The digital audience engaged with newspaper content reached a new high in March 2015, totaling 176 million adult unique visitors, a 10\% increase from March 2014 (Newspaper Association of America, 2015). Many of the largest newspapers' digital audience numbers far outpace circulation. For example, the New York Times reported an average weekday print circulation of less than 650,000 in September 2014 but their website and associated apps attracted nearly 54 million unique visitors in January 2015, and the majority of their paid circulation comes from digital sources (about 1.4 million) (Pew Research Center, 2015b). Television networks are also seeing high digital traffic, for example, the Cable News Network's (CNN's) website had about 64 million unique visitors in January 2015 and FoxNews.com had about 55 million unique visitors for the same time period (Pew Research Center, 2015c).

This ever-growing digital news world now boasts about 5,000 digital news sector jobs, 3,000 of which are at 30 digital-only news outlets (Pew Research Center, 2014a). Online newsrooms are typically composed of smaller staff than regular newsrooms. For example, the Seattle Post-Intelligencer went from 165 journalists to 20 when they moved their paper online (Cox, 2012). These new developments have changed how people access and interact with information. Essentially, these new communication systems have shifted from one-to-many (often one-way) communications to many-to-many, more interactive, webs of communication (O’Neill \& Boykoff, 2011).

\subsection{News Values in Traditional Media}

If someone was to read the front page of multiple national newspapers on a given day, or watch national news broadcasts from rival networks, they would typically find a broad similarity 
in the stories being covered and the order in which the content is presented (Allan, 2010). Journalists, editors, and all of the other individuals involved in the work of processing news apply a variety of practices or news values that help to determine what events are newsworthy and how these events should be reported (Allan, 2010).

There is extensive research literature concerned with news values, much of which elaborates upon a study conducted in the mid-1960s by Galtung and Ruge (1965). This section outlines the most commonly recognized news values, identified by Galtung and Ruge, and describes their application:

Frequency: the extent to which an issue fits into the news production cycle of a media organization. Issues that develop gradually tend to be ignored in favour of more immediate stories, unless a long-term issue reaches some kind of dramatic climax. For example, an oil spill in an ocean is more likely to be reported on than long term degradation of oceans due to persistent, long-term pollution.

Magnitude: there is a threshold that an issue must exceed before it will be considered newsworthy. An issue with a higher magnitude will get more extensive coverage than a lower magnitude issue. For example, the more violent a murder, the bigger the headlines it will make. Ambiguity: an issue's level of ambiguity determines its newsworthiness. An unambiguous event with clear interpretation is more likely to be covered than an ambiguous event from which many different interpretations can and will be made (Allan, 2010). For example, most people would agree that a local market burning down is a negative event but not everyone would agree that a new store opening in the neighbourhood is a positive event. Therefore, it is more likely that a store burning down would be reported on in the news than a store opening. 
Meaningfulness/Cultural Specificity: an issue's relation and relevance to the news audience's everyday lives and experiences (Allan, 2010). The culturally similar will be more relevant than the culturally distant (Allan, 2010). For example, if the majority of the audience does not practice Jainism, news relating to this ancient Indian religion would not be relevant and therefore would not likely be reported on.

Consonance: an issue that is in line with established views is more likely to be reported on, as familiar ideas are more easily received. For example, if it is well established that stabbing someone is not acceptable, it is likely that any reports on a stabbing will represent this established view.

Unexpectedness: in contrast to consonance, an event which is "out of the ordinary" or unanticipated does have media value (Allan, 2010), as epitomized by the saying, "Dog bites man isn't news, man bites dog is" (Allan, 2010).

Continuity: an issue that has already received coverage and been defined as news is more likely to continue to be covered for some time. This news value justifies an issue being in the news in the first place. For example, any new developments in a high-profile murder trial will be reported on regardless of the length of the trial.

Composition: a variety of types of events must be covered on any given day, thus some events may be chosen specifically to fill a news category or "news hole" (Allan, 2010). For example, if there are few stories available for the "arts news hole" than a story on a play that would not make the cut on a heavy news day may be reported on. Regional newspapers and newscast also generally have clearly marked sections for international, national, and local news (Allan, 2010). Personification: news tends to focus on the human element of events and deemphasize the more abstract "faceless" structures, forces, or institutions (Allan. 2010). People can act during a time 
span that fits within the news cycle whereas structures or forces may be more challenging to pin down in time and space. Also, it is possible to gather a full personal story through one or two interviews, while covering a structural or institutional issue may require numerous interviews, which is far too time-consuming for daily news.

Negativity: negative news is ordinarily preferred to positive news, namely because bad news conforms to more of the above news values, especially frequency, ambiguity, and unexpectedness (Allan, 2010). A positive development takes much more time and effort to achieve than a negative development, which is easily and swiftly achieved. Consider the time and effort discrepancies between building a home (positive) and destroying it in a fire (negative). Building a home is more challenging to fit into the news cycle because it would take months to complete, however destroying a home in a fire can unfold over a single news day. In addition, a negative event is much less ambiguous than a positive event. People are likely to similarly interpret bad news (such as a violent murder) whereas positive news may be positive to some but not to others. Finally, negative news is simply more unexpected and dramatic than positive news. Reference to Elite Nations: events that occur in countries that directly affect the audience's wellbeing are more likely to be covered than countries that do not have a large impact on the audience's lives (Allan, 2010). For example, an American citizen is much more likely to be interested in a story that is unfolding in the U.S. than one that is taking place in New Zealand. Reference to Elite Persons: actions performed by politicians, royalty, celebrities, and corporate leaders are far more relevant in news coverage than those of the general public (Allan, 2010). For example, the public is much more interested in Queen Elizabeth's opinion on a subject than a librarian's. 
Conflict: journalists typically frame their stories in a "balanced" way in order to remain objective in their reporting. Balance is achieved by getting two sides of every story. However, when these "sides" are conflicting, the potential for an interesting story is enhanced through dramatization (Allan, 2010). For example, the media will try to get both the plaintiff's and the defendant's side of a story for an article on a court case.

While news values vary between news organizations and are constantly changing, the news values outlined above, and those related, are consistently used to determine the newsworthiness of an event (Allan, 2010). A number of complex, chronic issues are often publically misunderstood due to regular application of these news values, which dictate what stories are covered and how they are presented to the public.

\subsection{Social Media}

Historically, people used the Internet to simply consume content: they read; they listened; and they watched (Kietzmann et al., 2011). Increasingly, people began using platforms, such as content-sharing sites (e.g. Reddit, Tumblr), blogs, social networks, and wikis, to generate, modify, share, and discuss content (Kietzmann et al., 2011). Social networking sites, in particular, have become so prevalent that the world's networked population has grown to 2.3 billion, representing $67.5 \%$ of all internet users worldwide (Chaffey, 2016). Through social media, citizens, NGOs, activists, journalists, corporations, and governments are now gaining greater access to information and more opportunities to engage in public discourse and influence the public agenda (Shirky, 2011).

Digital news content is frequently linked, shared, and discussed on platforms such as Facebook and, in particular, Twitter. In fact, many of the newly formed digital news outlets 
emphasize the importance of social media in storytelling and engaging their audiences (Pew Research Center, 2014a). This increase in news sharing on social media sites, unsurprisingly, has led to a spike in social media news consumption. Facebook and Twitter are growing as pathways for news consumption (Hermida, 2010; Pew Research Center, 2014b), as 63\% of both Facebook and Twitter users say that they get their news from these platforms (Pew Research Center, 2015e). While Facebook is used for a variety of discussions, Twitter is predominantly accessed for the news. The proportion of users who say they follow breaking news on Twitter is nearly double those who say they do so on Facebook (59\% vs. 31\%) (Pew Research Center, 2015e). This is especially true for developing, live events as over $85 \%$ of tweets are either breaking or persistent news (Kwak et al., 2010). In addition, the average Twitter user is two to three times more likely to visit a news website than is the average person (Farhi, 2009; Hermida, 2010), which is unsurprising given that news websites are the links most commonly shared by users (Chew \& Eysenback, 2010). Twitter is also being rapidly adopted by journalists as a vital instrument to distribute breaking news quickly and concisely, or as a tool to solicit story ideas, updates, and sources (Ahmad, 2010; Farhi, 2009; Hermida, 2010; Posetti, 2009).

Social media sites are distinctive because they enable users to take an active role in breaking, sharing, and commenting on news within their networks (Greenhow \& Reifman, 2009; Oeldorf-Hirsch \& Sundar, 2015). Participation in news events is increasingly common in the forms of content curation and sharing through Facebook and Twitter. These sites make content sharing incredibly simple and their platforms allow for seamless dissemination and discussion of news content (Oeldorf-Hirsch \& Sundar, 2015). Pew Research (2014) found that half of social network users have shared news stories, images, or videos, and 46\% have discussed a news event online. It has also been found that $26 \%$ of users have shared their own news photos and videos, 
playing a role in many breaking news events (Pew Research Center, 2014b). This novel form of news distribution and consumption may be altering journalistic norms (Murthy, 2013) and even creating an entirely new form of journalism (Hermida, 2010) by enabling the public to become more engaged with the news process (Papacharissi \& de Fatima Oliveira, 2012). Specifically, social networks represent a shift away from the traditional journalism paradigm of providing reports and analyses through narratives, and towards a multi-faceted and fragmented news experience (Dahlgren, 1996; Hermida, 2010).

\subsubsection{Twitter}

This research focuses on Twitter, which was selected because it is primarily a public platform, which means that the information that is shared is publicly accessible, unlike some social media applications, such as Facebook (White, 2013). It would be challenging to gather public discourse via Facebook as this social platform only allows access to public accounts, which are primarily organizations and companies. Furthermore, the public nature of Twitter allows for the collection and examination of online messages without the need for ethics approval (White, 2013).

Twitter is a social networking platform that allows users to create and view 140-character messages called tweets. As of 2015, 500 million tweets were generated per day (Twitter, 2015a). This platform is often used to provide information on breaking stories and for first-hand reporting of events as they occur. Journalists have hailed the immediacy of the platform which, in many cases, allows them to report breaking news more rapidly than most traditional media outlets (Castillo et al., 2011). The site supports additional material such as links, photos, and videos which aid in the dissemination of information. Twitter is also commonly used to discuss 
long-term issues and events that unfold over months or years and provides a platform for largescale dialogue (Bruns \& Burgess, 2012).

Twitter conversations are often incorporated in traditional news coverage of major events. To keep up with evolving stories, news organizations have started publishing liveblogs with a combination of unverified videos, photos, anonymous tweets, and traditional sources (Hermida, 2010; Stelter, 2009). For example, the $B B C$ included unverified tweets alongside material from correspondents in breaking news coverage of the Mumbai bombings in 2008 (Hermida, 2010); the $B B C$ justified this on the grounds that there was a case "for simply monitoring, selecting and passing on the information we are getting as quickly as we can, on the basis that many people will want to know what we know and what we are still finding out" (Herrmann, 2009). This new practice of choosing tweets to include in their coverage may enable journalists to maintain their gate-keeping role (Farhi, 2009; Hermida, 2010), but because some tweets contain unverified information, their inclusion in news reports has the potential to advance the spread of misinformation.

One of the most powerful information spreading tools on Twitter is the retweet. A retweeted tweet reaches an average of 1,000 users regardless of the number of followers of the original tweeter (Kwak et al., 2010). Once retweeted, a tweet is almost instantly retweeted again, demonstrating fast information diffusion (Kwak et al., 2010). Retweets occur in a highly competitive environmental in which countless messages are fighting for attention. A retweet signals that the message is important, demonstrates public agreement with the message, represents the credibility of the original messenger, and indicates whose opinion is regarded as important or invalid (Choi, 2014). 


\subsubsection{Misinformation Spread through Social Media}

While numerous benefits arise from the wealth of information now available at the touch of a keyboard, ubiquitously present social media platforms, such as Twitter, also have the ability to spread rumours, innuendo, conspiracy theories, and misunderstandings at the speed of electricity (Pierpont, 2011). Since social media has become one of the primary means by which people learn about worldwide developments (Jin et al., 2014), its ability to spread erroneous information could lead to an ill-informed public or even cause unnecessary panic (Nguyen, 2008).

A number of factors lead to inaccurate information circulating the internet. Journalists, commenters, and other social media users often struggle to understand the complexities of technical stories, especially when there are rapid developments and pressure to promptly report new information (Pierpont, 2011), leading to little time to digest the story and look deeper into what is being reported. This struggle can be exaggerated when reporting on events in foreign nations and early or more detailed reports are in an unfamiliar language (Pierpont, 2011). While some users will provide reliable facts from external sources, many users generate information by providing first-person observations (Castillo et al., 2011). Anyone with internet access can express their opinions and provide unverified information (Pierpont, 2011). Then, from this pool of information, other users synthesize and elaborate to produce derived interpretations in a continuous process (Castillo et al., 2011). This process can gather, filter, and propagate information very rapidly, but it may not be able to separate fact from fiction (Castillo et al., 2011).

Dissemination of misinformation over social media has been documented for many events, including the 2009 swine flu outbreak (Nguyen, 2008), the 2011 nuclear disaster in Fukashima (Pierpont, 2011), and the 2014 Ebola outbreak. In the last case, online rumours developed such 
as that Ebola could be airborne in some cases, that there was a suspected Ebola case in Kansas City, and even that health officials might inject Ebola patients with lethal substances (Jin et al., 2014). In some cases, rumours that originate on Twitter can even end up in reputable news sources, causing further misinformation spread. For example, during riots in London in 2011, a number of rumours were circulating social media sites but one rumour (that rioters broke into a branch of McDonald's and cooked their own food) ended up in a story by the Daily Mail, with the headline, "Youths storm McDonald's and start cooking their own food" (Richards \& Lewis, 2011). This story was shared on Twitter with a potential audience of at least 20,000 users, not including the readers of the Daily Mail article itself. This collection of tweets demonstrated that, "the mainstream media is perfectly capable of picking up juicy unverified information from social media and, without adhering to the usual standard of fact checking, running with a story that is in the end not verified, but goes unchallenged" (Richards \& Lewis, 2011).

The spread of misinformation is burgeoning with the use of the retweet feature on Twitter. The 140-character limit, the common practice of adding comments, and other factors prompt users to alter or paraphrase the original message (Boyd et al., 2010). Furthermore, attribution is inconsistent (Boyd et al., 2010) so it may be challenging for people to find the original source. As a result, the text and meaning of messages often change as they are shared (Boyd et al., 2010). It has also been found that sensational Twitter topics have a high chance of being retweeted, which widens the audience, sometimes to the point where the topic becomes a trend (Morozov, 2009). Once a topic is trending, users that are not connected to the social network that originated the information can view and share it, thus expanding the potential audience to all Twitter users (Morozov, 2009). 
Another factor that may influence the spread of misinformation is the lack of any real correlation between social shares and people reading the links they are sharing (Jeffries, 2014). Chartbeat, a company that measures real-time traffic for websites, found that people only spend a few seconds on an article before tweeting it to their followers (Jeffries, 2014). It has also been speculated that many users do not read beyond an article's headline before commenting on a post (NPR, 2014).

Misinformation may also spread on social media due to social tendencies that result in echo chambers. While social media provides greater access to a variety of information, research demonstrates that individuals have a propensity to predominantly focus on information that supports their existing views. In addition, people are inclined to primarily interact with likeminded individuals (Colleoni et al., 2014). This selective exposure and ideological segregation results in an echo chamber, which reinforces established viewpoints and opinions and limits the information that people are exposed to (Barbera et al., 2015; Bimber \& Davis, 2003; Colleoni et al., 2014; Davis, 1999; Galston, 2003; Mutz \& Martin, 2001; Noveck, 2000; Sunstein, 2001; Wilhelm, 1998). People may be misinformed about an issue if they are not being exposed to information outside of their preferred viewpoints.

While the majority of information on Twitter is, in fact, accurate, misinformation and subsequent misunderstanding can easily spread to large audiences due to the nature of information flow through the Twitter network (Scanfeld et al., 2010). For example, researchers from Columbia University looking at misunderstanding about antibiotics in Twitter content, found there were only about 700 tweets containing misinformation on antibiotics out of a sample of 52,000; however, just 302 of these inaccurate tweets reached an audience of 850,375 followers (Scanfeld et al., 2010). 


\subsection{Climate Change Science in Traditional Media}

Climate change science communication in traditional media has been extensively researched since its rise in popularity through the 1960s and into the 1990s. This section will outline the history of climate change in the media and discuss the "news values" that are applied to environmental journalism.

\subsubsection{The Rise of Climate Change Communication}

Environmental news coverage became more consistently featured in a handful of news organizations in the 1960s (Wyss, 2008) and picked up steam after Rachel Carson published Silent Spring (1962) (Palen, 1999). Journalists found themselves covering issues such as dioxin, smog, oil spills, air pollution, nuclear fallout, and endangered species; some newspapers even created an environmental beat (Palen, 1999). By 1990, the field of journalism was given a boost with the creation of the Society of Environmental Journalists (SEJ) (Cox, 2012), an organization which aims to "strengthen the quality, reach, and viability of journalism across all media to advance public understanding of environmental issues" (SEJ, 2015). The SEJ was founded by a small group of award-winning journalists from National Geographic, The Philadelphia Inquirer, Turner Broadcasting, USA Today, and Minnesota Public Radio (SEJ, 2015). Within nine years of its inception, the organization was publishing a quarterly journal and holding national conferences, was made up of more than 1,100 members, and had a grant funded, $\$ 350,000$ budget (Palen, 1999). By 1997 the SEJ was the most significant organization of environmental journalists in the United States (Palen, 1999).

The 1990s saw the beginning of research activity on climate change communication. Much of this research focused on the countries that are responsible for climate change, with only 
a handful of studies on the countries that are most affected by the negative impacts of a changing climate (Schäfer \& Sclichting, 2014). Overall, European countries receive the largest share of analyses and North American countries - Canada, Mexico, and the United States - receive the second largest share of scholarly attention (Schäfer \& Sclichting, 2014). This research has demonstrated that news entities act as the primary source of climate change information for laypeople as well as for stakeholders and decision-makers (e.g. Arlt, et al, 2011; Schäfer, 2012a; Schäfer \& Sclichting, 2014; Stamm, et al., 2000). News organizations have even been described as, "important arenas and important agents in the production, reproduction, and transformation of the meaning" of climate change (Carvalho, 2010; Schäfer \& Sclichting, 2014). One study found that the majority of Americans get most of their scientific news and information from the news media, whether this is through the Internet (44\%), television (31\%), or newspapers (8\%) (Jones et al., 2014).

Due largely to this dependence, traditional media strongly shape the public's perception of the importance of climate change (Cox, 2012). The news media filters or selects issues for attention, telling people not what to think but what to think about (Cohen, 1963). It has been said that when an issue has become a priority within the media, it has reached "celebrity status" as a social problem (Boykoff \& Boykoff, 2007; Ungar, 1992). Attention to one issue suggests that another issue may be overlooked (Keller, 2009) and the media tends to present a common, and limited, range of issues - restricting the breadth of focus and concern (McCombs \& Shaw, 1972).

\subsubsection{News Values and Climate Change}

The news values applied to environmental issues have been found to influence and impede accurate reporting of climate change science (Cox, 2012), contributing to informational 
bias and leading to content-deficient journalistic reporting of climate change issues (Anderson 2008; Boykoff \& Boykoff, 2007). This section summarizes the documented characteristics of climate change reporting that negatively impacts the dissemination of climate change science. This section will also outline the traditional news value(s) to which each characteristic relates.

\subsubsection{Novelty (News Value: Unexpectedness)}

Conventionally, a story that has already been covered is not worth telling for journalists, as epitomized by Stocking and Leonard's view that, "It ain't news unless it's new" (Stocking \& Leonard, 1990). Reporters will reject stories that have already been printed in favour of writing something that is fresh, distinctive, or has a novel angle. This leads to an "issue-of-the-month syndrome" that makes environmental issues unappealing when there is nothing new or exciting to report (Boykoff \& Boykoff, 2007; Stocking \& Leonard, 1990). Therefore, environmental news is often focused on major crises or events that are closely tied to the 24-hour daily news cycle such as oil spills or tsunamis, rather than unobtrusive, chronic issues such as climate change (Cox, 2012). This coverage often overlooks the underlying causes and long-term consequences of these events, leading to an inadequate understanding of complex and interconnected environmental issues (Boykoff \& Boykoff, 2007; Cox, 2012).

\subsubsection{Dramatization (News Value: Negativity and Unexpectedness)}

Strongly tied to novelty is dramatization, which reflects the tendency of journalists to emphasize disaster over stability and the present over the past or future, to downplay complex policy information, and to focus on the spectacular details that sit at the surface of events, avoiding comprehensive analysis of the enduring issues (Boykoff \& Boykoff, 2007). 
Dramatized coverage can trivialize news content and result in under-reporting of issues that do not present an immediate sense of controversy or excitement. This has led to sensationalized or alarmist reporting of environmental issues (Boykoff \& Boykoff, 2007).

\subsubsection{Personalization (News Value: Personification)}

Personalization de-emphasises environmental or political complexities and highlights human trials, tribulations, and triumphs, conforming to the idea that news should center on personalities and individuals rather than on big picture issues or social processes. These personalized stories seldom analyze social, scientific, or political issues in depth (Boykoff \& Boykoff, 2007). These stories provide a human connection to an event or issue but rarely comprise a comprehensive discussion surrounding root-causes, other impacts, future-risks, or preventative actions to mitigate future issues (Boykoff \& Boykoff, 2007).

\subsubsection{Balance and Objectivity (News Value: Conflict)}

As stated in section 4.2, journalists often use balance as a tool for objectivity. In science journalism, balance is obtained by presenting the opposing views of "credible" spokespersons with equal attention. This is often used as a crutch in climate reporting for journalists who lack scientific understanding or who have strict time constraints (Cox 2012). This commonly used tool is damaging to climate science as it presents a "dueling experts" scenario where opposing experts are given equal weight, creating the appearance of significant disagreement within the science community. This approach ignores the fact that in most cases one "side" is backed up by thousands of highly reputable climate scientists who have published work in peer-reviewed publications, while the other "side" is often composed of a few skeptics whose work has likely 
not gone through the peer-review process (Boykoff \& Boykoff, 2007). The aura of scientific uncertainty created by balanced reporting is a powerful political tool, as it allows politicians to avoid action and call for further research (Boykoff \& Boykoff, 2007).

A study by Boykoff (2007) found that, over a 15-year period, more than half of the news articles looked at featured a balance of opinions regarding anthropogenic climate change. It was demonstrated that this coverage was divergent from the IPCC dialogue in a statistically significant way (Boykoff \& Boykoff, 2007). This divergence represents how balance in news creates an informational bias (Boykoff \& Boykoff, 2007).

\subsubsection{Authority Order (News Value: Reference to Elite Persons)}

Journalists who do not have a background in environmental science or who have strict time constraints tend to overly rely on authority figures, such as government officials, business leaders, and law enforcement agencies. These figures become "primary definers" of environmental events and reassure the public that an issue is being effectively addressed (Anderson 2008; Boykoff \& Boykoff, 2007). Research has demonstrated that through climate change news, the public often accepts and trusts these authority figures' messages. This public trust of government sources can influence policy decisions surrounding climate change, due to acceptance of their decisions, with little pressure to reassess. Since climate change issues frequently appear in the media, this penchant for expert or authoritative voices is a widespread phenomenon (Boykoff \& Boykoff, 2007). 


\subsubsection{Root Causes of Biased Media}

There are three well documented reasons why the news media presents deficient coverage of climate change science; these include the power of ownership and economic interests, downsizing, and the lack of available expertise. This section will detail the root causes of the media's reliance on news values to cover climate change.

\subsubsection{Political Economy and Gatekeeping}

Media political economy refers to the power of ownership and the influence of the financial interests of owners on news content. It has been demonstrated that the majority of news entities are owned by multinational corporations that also have economic interests in businesses which are impacted by environmental regulations, such as oil wells, pulp and paper mills, electric utilities, energy companies, and forestry (Cox, 2012). The gatekeeping role is assumed by the journalists and editors who filter information before it is passed to the public (White, 1950). Gatekeeping decisions could be influenced by media political economy and journalists may rely on news values, such as authority order and balance to downplay environmental issues (Cox, 2012).

\subsubsection{Downsizing}

While newspapers are facing more severe economic problems than other media, many traditional news entities have experienced severe fluctuations in staff sizes in recent years (Pew Research Center, 2011). For example, newspaper revenue has dropped nearly $50 \%$ in the last four years and continues to fall (Cox, 2012). This income loss has led to major downsizing in circulation, newspaper size, space for specialized or complex topics, and number of journalists 
(Cox, 2012). In 2011, Pew Research Center found that newspapers had lost $25 \%$ of their daily circulation since 2000 and that there were $30 \%$ fewer reporters and editors in newsrooms than in 2000 (Pew Research Center, 2011). In 2014, both daily and Sunday circulation fell another 3\% (Pew Research Center, 2015c). With much smaller staff sizes, most of these newspapers now rely on content aggregators.

Downsizing is also occurring in news broadcasting. For example, in 2015, Bell Media, which owns 30 local TV stations and 34 specialty channels, laid off 380 staff, including editorial staff, news anchors, and reporters (Friend, 2015); also in 2015, BBC announced that it will cut more than 1,000 jobs by April 2017 in order to close a $\$ 235$ million budget gap caused by a decrease in households watching live television (BBC, 2015). In 2014, the Canadian Broadcasting Corporation (CBC) announced the company's strategy to downsize by $25 \%$ over the next five years and cut 144 positions across Canada in 2015 as part of that five-year plan (Szklarski, 2015); also, in 2014, CNN cut 150 jobs and canceled several shows (Hart, 2014). Brian Stelter, the host of $C N N$ 's media commentary program, "Reliable Sources," said the $C N N$ layoffs were a result of an industry under strain (Hart, 2014).

In addition, science or environmental "beat" reporters are often let go in favour of generalists who can cover a wide-variety of topics (Moser, 2010). For example, in 2008, CNN's entire science and environment staff was let go (Cox, 2012).

The remaining reporters are often urged to create entertaining news that will draw an audience. Daily newspapers commonly make between 70 and $80 \%$ of their revenue from advertising (Filloux, 2012), while cable news channels (such as CNN and FoxNews) gain revenue from two chief sources - advertising and subscriber fees (Pew Research Center, 2015d). The more readers/viewers a news organization has, the more businesses will be interested in 
paying for ad space (Filloux, 2012). This is where novelty, dramatization, and personalization become easy tools for journalists to ramp up their coverage of environmental issues. Unobtrusive or invisible stories that slowly develop over many years are challenging to fit into the conventional news format (Cox, 2012). Journalists will instead focus on stories that involve exciting, new disasters that fit into the 24-hour daily cycle (Cox, 2012).

\subsubsection{Lack of Expertise}

Due to diminished revenue, news organizations cannot afford to hire environmental or scientific specialists so the journalists who are covering these issues likely do not have the scientific training or knowledge necessary to discuss technical issues in depth (Anderson, 2008; Cox, 2012). In fact, it has been reported that only $12 \%$ of environmental journalists have degrees in environmental or scientific fields (Wyss, 2008). This lack of expertise leads to a reliance on balance and authority knowledge.

\subsection{Limited Research for Climate Change Communication on Twitter}

The capabilities of social media have expanded immensely and now social media can magnify existing social divisions, draw limited available attention to sensationalized reports, and widely spread misinformation without quality control (Moser, 2010). Limited empirical research on climate change communication using social media is available (Koteyko et al., 2013; Moser, 2010). At $67.5 \%$, more than two-thirds of all research on media representations of climate change (from 1957-2010) focuses on print media (Schäfer \& Sclichting, 2014). During the last decade, it has been found that $16 \%$ of all analyzed media were online media, with only $4.5 \%$ focusing on social media and Web 2.0 formats, including blogs, discussion forums, and video 
platforms like YouTube (Schäfer \& Sclichting, 2014). To date, there have been no studies that analyze climate change communication on Twitter to the best of the present author's knowledge.

One-way information delivery systems and two-way, interactive dialogic forms of communication have very different potential impacts, benefits, and limitations (Moser, 2010). Reader comments on climate change coverage contribute to the diverse, complex, and disputed field, and thereby have the potential to shape thinking and public discourse around this environmental phenomenon (Koteyko et al., 2013). Therefore, it is imperative that the role of social media in the communication of climate change is analyzed (Moser, 2010). 


\section{Social Network Analysis of Climate Change Discussion on Twitter During COP21}

This study evaluates discussions on Twitter during the 2015 United Nations Conference on Climate Change (COP21) to elucidate the social media platform's role in communicating climate change information. For a five-day period, links embedded in a sample of tweets containing "\#climatechange" were characterized, Twitter users were classified by the types of links they typically shared, and their degree centralities (the number of connections for each user) were measured. There was little skeptical content across all user categories; however, news links were more likely than non-news to contain content that is skeptical of climate change. Users who typically shared skeptical news links and users who typically shared non-skeptical non-news links exhibited a relatively high number of connections with other users.

Climate change has devastating implications for food and water supplies, energy production and use, ecosystem and species survival, human health, and social and political stability (IPCC, 2014; Stamm et al., 2000). It is a challenging policy dilemma that requires international cooperation of unprecedented complexity (Lorenzoni et al., 2007; Rice et al., 2015). The situation is exacerbated by the fact that the majority of the public does not understand climate change science nor believe that climate change is a priority (Leiserowitz et al., 2010; Pew Research Center, 2016 Shuckburgh, et al. 2012).

Gallup polls conducted in 2007 and 2008 measured climate change awareness in 127 countries and found that $40 \%$ of adults worldwide had never heard of climate change; this rose to more than $65 \%$ in some developing countries, such as Egypt, Bangladesh, and India (Pelham, 2009). In North America, Europe, and Japan, many citizens have been found to misunderstand climate change and underestimate its importance. For instance, a 2010 study graded the 
American public's knowledge and understanding of climate change by conducting a survey regarding the climate system and the causes, impacts, and potential solutions to climate change. The study found that $52 \%$ received an $\mathrm{F}(<60 \%$ correct) and only $1 \%$ received an A $(>89 \%$ correct) (Leiserowitz et al., 2010). Other studies have found that less than half of the public in the U.S. believe climate change is caused by anthropogenic forces (Jones et al., 2014; Weber \& Stern, 2011). In addition, Jones et al. (2014) found that only four out of ten Americans believe that there is significant consensus amongst scientists regarding global warming. Similar confusion about climate change science has been recorded in the United Kingdom. A 2011 survey looking at the public's perception of climate change in the UK, found that one-third of respondents do not trust climate scientists to tell the truth about climate change and almost half of the respondents believe that the seriousness of climate change is exaggerated (Shuckburgh, et al. 2012). In another survey, conducted in 2004, only $30 \%$ of the British respondents correctly named carbon dioxide as the main gas contributing to climate change (Norton and Leaman, 2004).

A survey conducted by Pew Research Center (2016) found that citizens of countries with high levels of carbon emissions expressed less concern regarding climate change. American and Chinese citizens, whose countries have the highest overall carbon dioxide emissions, are among the least concerned about climate change. The survey found that only 18\% of Chinese and $45 \%$ of Americans think climate change is a very serious problem (Pew Research Center, 2016).

These findings are troubling because the leading international body for the assessment of climate change, the Intergovernmental Panel on Climate Change (IPCC), has demonstrated that climate change is occurring for anthropogenic reasons and people are currently and will continue to suffer globally from negative effects (IPCC, 2014). 
The news media is the largest source of climate change information for the public; however, due to ownership influence, retrenchment, and lack of expertise, the media often resorts to a number of journalistic "news values" that can misconstrue climate change science (Rice et al., 2015; Stamm et al., 2000). The media's representation of climate change has left the public with a flawed understanding of the current situation (Leiserowitz et al., 2010).

The public is increasingly turning to social media to get climate change information (Schäfer, 2012b); however, to date, social media platforms are poorly understood in terms of how climate change information is shared.

\section{Literature review}

\section{Climate change science in traditional media}

The 1990s saw the beginning of research activity on climate change communication. Much of this research focused on the countries that are responsible for climate change, with only a handful of studies on the countries that are most affected by the negative impacts of a changing climate (Schäfer \& Sclichting, 2014). Overall, European countries receive the largest share of analyses and North American countries - Canada, Mexico, and the United States - are the second largest focus for scholarly attention (Schäfer \& Sclichting, 2014). This research has demonstrated that news entities act as the primary source of climate change information for laypeople as well as for stakeholders and decision-makers (e.g. Arlt et al., 2011; Schäfer, 2012a; Schäfer \& Sclichting, 2014; Stamm et al., 2000).

Due largely to this dependence, traditional media strongly shapes the public's perception of the importance of climate change (Cox, 2012). The news media filters or selects issues for attention (Cohen, 1963); in fact, when an issue has become a priority within the media, it has 
reached "celebrity status” as a social problem (Boykoff \& Boykoff, 2007; Ungar, 1992).

Attention to one issue suggests that another issue may be overlooked (Keller, 2009) and the media tends to present a common, and limited, range of issues - restricting the breadth of focus and concern (McCombs \& Shaw, 1972).

The detrimental effects of this content filtering by news agencies is exacerbated by the lack of variety of content between news sources. If someone was to read the front page of multiple national newspapers on a given day, or watch national news broadcasts from rival networks, they would typically find similarity in the stories being covered and the order in which the content is presented (Allan, 2010). This is because journalists and editors apply a variety of practices or news values that help to determine what events are newsworthy and how these events should be reported (Allan, 2010). Many of these news values are adapted to environmental reporting and have been found to impede accurate coverage of climate change science (Cox, 2012). Now, the public is increasingly turning to the Internet and social media to get climate change information.

\section{Social media}

Historically, people used the Internet to simply consume content: they read; they listened; and they watched (Kietzmann et al., 2011). Increasingly, people began using platforms, such as content-sharing sites (e.g. Reddit, Tumblr), blogs, social networks, and wikis, to generate, modify, share, and discuss content (Kietzmann et al., 2011). Social networking sites, in particular, have become so prevalent that the world's networked population has grown to 2.3 billion, representing $67.5 \%$ of all internet users worldwide (Chaffey, 2016). Through social media, citizens, NGOs, activists, journalists, corporations, and governments are now gaining 
greater access to information and more opportunities to engage in public discourse and influence the public agenda (Shirky, 2011).

Digital news content is frequently linked, shared, and discussed on platforms such as Facebook and, in particular, Twitter. In fact, many of the newly formed digital news outlets emphasize the importance of social media in storytelling and engaging their audiences (Pew Research Center, 2014a). Facebook and Twitter are growing as pathways for news consumption (Hermida, 2010; Pew Research Center, 2014b), as 63\% of both Facebook and Twitter users say that they get their news from these platforms (Pew Research Center, 2015e). While Facebook is used for a variety of discussions, Twitter is predominantly accessed for the news. The proportion of users who say they follow breaking news on Twitter is nearly double those who say they do so on Facebook (59\% vs. 31\%) (Pew Research Center, 2015e). This is especially true for developing, live events as over $85 \%$ of tweets are either breaking or persistent news (Kwak et al., 2010). Twitter is also being rapidly adopted by journalists as a vital instrument to distribute breaking news quickly and concisely, or as a tool to solicit story ideas, updates, and sources (Ahmad, 2010; Farhi, 2009; Hermida, 2010; Posetti, 2009).

Social media sites are distinctive because they enable users to take an active role in breaking, sharing, and commenting on news within their networks (Greenhow \& Reifman, 2009; Oeldorf-Hirsch \& Sundar, 2015). Participation in news events is increasingly common in the forms of content curation and sharing through Facebook and Twitter. These sites make content sharing simple and their platforms allow for seamless dissemination and discussion of news content (Oeldorf-Hirsch \& Sundar, 2015). Pew Research Center (2014a) found that half of social network users have shared news stories, images, or videos, and $46 \%$ have discussed a news event online. It has also been found that $26 \%$ of users have shared their own news photos and videos, 
playing a role in many breaking news events (Pew Research Center, 2014b). This novel form of news distribution and consumption may be altering journalistic norms (Murthy, 2013) and even creating an entirely new form of journalism (Hermida, 2010) by enabling the public to become more engaged with the news process (Papacharissi \& de Fatima Oliveira, 2012). Specifically, social networks represent a shift away from the traditional journalism paradigm of providing reports and analyses through narratives, and towards a multi-faceted and fragmented news experience (Dahlgren, 1996; Hermida, 2010).

\section{Method}

The purpose of this study is to elucidate the role of social media in communicating climate change knowledge and, in particular, to study how certain types of users impact the availability and quality of this knowledge. Specifically, climate change discussions were monitored on Twitter during the 2015 United Nations Conference on Climate Change (COP21). The links embedded in each tweet were characterized and the tendency of users to share links of differing characteristics was determined. By creating classifications for various types of users and studying their relative centrality, a more nuanced understanding of how social media affects climate change communication is provided.

\section{Twitter}

This research focuses on Twitter, which was selected because it is primarily a public platform, unlike some social media applications, such as Facebook (White, 2013). Twitter is a 
social networking platform that allows users to create and view 140-character messages called tweets. As of 2015, 500 million tweets were generated per day (Twitter, 2015a). This platform is often used to provide information on breaking stories and for first-hand reporting of events as they occur. Journalists have hailed the immediacy of the platform which, in many cases, allows them to report breaking news more rapidly than most traditional media outlets (Castillo et al., 2011). The site supports additional material such as links, photos, and videos which aid in the dissemination of information. Twitter is also commonly used to discuss long-term issues and events that unfold over months or years and provides a platform for large-scale dialogue (Bruns \& Burgess, 2012).

Twitter conversations are often incorporated in traditional news coverage of major events. To keep up with evolving stories, news organizations have started publishing liveblogs with a combination of unverified videos, photos, anonymous tweets, and traditional sources (Hermida, 2010; Stelter, 2009). This new practice of choosing tweets to include in their coverage may enable journalists to maintain their gate-keeping role (Farhi, 2009; Hermida, 2010), but because some tweets contain unverified information, their inclusion in news reports has the potential to advance the spread of misinformation.

One of the most powerful information spreading tools on Twitter is the retweet. A retweeted tweet reaches an average of 1,000 users regardless of the number of followers of the original tweeter (Kwak et al., 2010). Once retweeted, a tweet is almost instantly retweeted again, demonstrating fast information diffusion (Kwak et al., 2010). A retweet signals that the message is important, demonstrates public agreement with the message, represents the credibility of the original messenger, and indicates whose opinion is regarded as important or invalid (Choi, 2014). 
The capabilities of social media have expanded immensely and now social media can magnify existing social divisions, draw attention to sensationalized reports, and widely spread misinformation without quality control (Moser, 2010). While social media provides greater access to a variety of information, research demonstrates that individuals have a tendency to predominantly focus on information that supports their existing views and interact with likeminded individuals. This selective exposure and ideological segregation results in echo chambers, which reinforce established viewpoints and opinions (Barbera et al., 2015; Bimber \& Davis, 2003; Colleoni et al., 2014; Davis, 1999; Galston, 2003; Mutz \& Martin, 2001; Noveck, 2000; Sunstein, 2001; Wilhelm, 1998). Limited empirical research on climate change communication using social media is available (Koteyko et al., 2013; Moser, 2010). More than two-thirds of all research on climate change communication (from 1957-2010) focuses on print media (Schäfer \& Sclichting, 2014). During the last decade, it has been found that $16 \%$ of all analyzed media were online media, including blogs, discussion forums, and video platforms such as YouTube, with only $4.5 \%$ focusing on social media and Web 2.0 formats (Schäfer \& Sclichting, 2014). To date, no studies that analyze climate change communication on Twitter have been identified.

One-way information delivery systems and two-way, interactive dialogic forms of communication have very different potential impacts, benefits, and limitations (Moser, 2010). Reader comments on climate change coverage contribute to the diverse, complex, and disputed field, and thereby have the potential to shape thinking and public discourse around this environmental phenomenon (Koteyko et al., 2013). Therefore, it is imperative that the role of social media in the communication of climate change is analyzed (Moser, 2010). By 
understanding how climate change information is disseminated on digital platforms, more effective communication may be attainable.

\section{Data collection program}

Data associated with tweets were collected using the online program, Netlytic, which is, "a cloud-based text and social network analyzer that can automatically summarize large volumes of text and discover social networks from online conversations on social media sites such as Twitter, YouTube, blogs, online forums and chats" (Netlytic, 2013; White, 2013). For all tweets containing the hashtag "\#climatechange" between Dec. 4th and Dec. 8th, the text provided in each tweet, the username of the tweet's author, and the date of each tweet were collected. The collected data were then exported to a spreadsheet in order to characterize the links provided in each tweet. Separately, a social network analysis was conducted using Netlytic's built-in analysis tools (Netlytic, 2013), which provided, for each user, the degree centrality (i.e., the number of connections that a given user has).

\section{Hashtags}

The hashtag "\#climatechange" was selected because research has shown that awareness of climate change on Twitter is chiefly expressed using this hashtag (Hamed, et al. 2015). Additionally, \#climatechange was determined to be a "key" hashtag as it was used often and was highly correlated to the terms "climate", "climate change", and "climate action" (as measured by Netlytic's keyword extractor, which is used to identify optimal keywords).

Hashtags are an important feature of Twitter; by including them in tweets, users can facilitate an unrestricted conversation on a specific topic (Lotan et al., 2011; White. 2013). Using 
hashtags as keywords to collect tweets is an effective method to gather data on a topic and it is also well-established in the literature (Bajpai \& Jaiswal, 2011; Gaffney, 2010; Papacharissi \& de Fatima Oliveira, 2012; Segerberg \& Bennett, 2011; White, 2013). Using the most prominent or "key” hashtag for analysis is also common (Bajpai \& Jaiswal, 2011; Gaffney, 2010; Lotan et al, 2011, Papacharissi \& de Fatima Oliveira, 2012; White, 2013). Using "key" hashtags for data collection does have its limitations (White, 2013); some relevant tweets may have been missed.

\section{Collection period and sample size}

Data were collected from Nov. 13th until Dec. 14th; surrounding the 2015 United Nations Conference on Climate Change, which took place Nov. 30th through Dec. 11th. This procedure resulted in 785,805 tweets, which were automatically separated into data sets of approximately 100,000 tweets by Netlytic. These sets of data cannot be combined in Netlytic, so one set of around 100,000 tweets was chosen for analysis. The set chosen was a five-day period from Dec. 4th to Dec. 8th, which was in the middle of the 2015 conference. This period was chosen because past climate change conferences have coincided with a peak in global newspaper reporting on climate change. Such peaks in coverage were previously evident during the Bali Climate Change Conference in 2007, the Copenhagen Climate Change Conference in 2009, and the Lima Climate Change Conference in 2014 (Luedecke et al. 2015).

The 2015 United Nations Conference is of particular interest because many scientists and world leaders considered it to be one of the last opportunities to form an agreement to keep human-induced warming below 2 Celsius degrees and limit the severest impacts of climate change (Sustainable Development Solutions Network, 2015). COP21 ended with a universal, 
legally binding global climate agreement that was adopted by 195 countries (European Commission, 2016).

The chosen dataset of nearly 100,000 tweets was too large for analysis and therefore a sample was chosen. From the five-day period, users and their tweets were randomly selected for analysis until approximately 3000 tweets were collected. In order to accurately classify the user by the type of links they predominantly share, each had to be an active tweeter and have sent at least four tweets to be chosen for analysis. This minimum threshold was selected to avoid the risk in classifying users based on a small number of tweets that might not reflect their behaviour outside of the five-day data collection window. In cases where a user had greater than 30 tweets, a representative sample of 30 randomly selected tweets was coded and analyzed. This allowed users to be efficiently characterized based on a suitable amount of user content. Any tweet that was a duplicate or was not written in English was removed. This resulted in a sample of 2,849 tweets from 368 Twitter users. Each of the users' unique tweets and retweets in this sample were coded and analyzed.

\section{Text analysis for news links and non-news links}

These 2,849 tweets contained 2,718 links which were each coded and analyzed. A manual text analysis was conducted to categorize the links within the tweets (i.e., a link lead to a news website or to a non-news website) and to categorize the news links as either alternative or mainstream (Clarke, 2012; Lovejoy \& Saxton, 2012; White, 2013). News sources were defined as webpages for any newspaper, magazine, television broadcaster, radio broadcaster, or news agency (wire service). If the organization's self-proclaimed main purpose was as a source of news, then it was considered a link to a news source. Any other source was considered non- 
news. Mainstream media were defined as any news entities that appear on the Pew list of the top 50 online news entities (Grefe, 2015), as well as any additional news entities that exist offline, such as in print, radio, or television (e.g. The Toronto Star, National Geographic, Al Jazeera). Alternative news was defined as any news entity that does not appear on the Pew list of top 50 online news entities, exists only online, or describes itself as independent/alternative media (e.g. Indymedia, Free Speech TV, The Raw Story) (Segerberg \& Bennett, 2011).

\section{Social network analysis for news links and non-news links}

A social network analysis was also conducted. Social networks have been used in a variety of related studies (Diani, 1995; Gaffney, 2010; Sullivan \& Xie, 2009; White, 2013) and are useful to study online phenomenon because they offer "the tools to interpret the structure of the network" and identify patterns of connections between individuals (Diani, 2002; White, 2013). Simply put, a social network analysis measures the flow of information between individuals within a group. For this research, Twitter users were the individuals and the retweets, replies, or mentions among the users were their connections (White, 2013).

Users were categorized by the types of tweets they predominantly shared. Categorizing users this way made it possible to see what type of information was highly retweeted and mentioned within the network of users. During categorization, a retweet was considered an amplifying tool because of the large number of users which are reached on average (Kwak et al., 2010). The users were placed into one of five categories:

News Provider: a user with more than $50 \%$ of their posts being original posts and more than $50 \%$ of their links are to a news source; 
Non-News Provider: a user with more than 50\% of their posts being original posts and more than $50 \%$ of their links are to a non-news source;

News Amplifier: a user with more than 50\% of their posts being retweets and more than $50 \%$ of their links are to a news source;

Non-News Amplifier: a user with more than 50\% of their tweets being retweets and more than $50 \%$ of their links are to a non-news source; and

Other: a user that did not fit into one of the categories above.

Degree centrality, a common measurement used in social network analysis, was measured for each user in the network. This measurement originated in the socioeconomic concept of the 'star' - the person in a group who stands at the center of attention (Scott, 1991). Degree centrality helps to determine which users have the most connections with other users in a conversation. The users with the highest number of connections are at the center of the conversation and are therefore considered the most influential (Gaffney, 2010; Netlytic, 2013). For this research, degree centrality was characterized as the number of unique Twitter users with whom a user communicated on Twitter, including re-tweets, replies, and mentions (White, 2013). Three degrees of centrality were applied: in-degree, out-degree, and total degree centrality. In-degree centrality was the number of connections a user received; out-degree was the number of connections a user sent out; and total degree centrality was the merging of indegree and out-degree connections (Scott, 2000; White, 2013). The total mean degree centrality was measured for each of the five types of users outlined above in order to determine what type of information was most shared and discussed. In order to compare the different user categories' mean degree centralities, an ANOVA test was completed to determine if there were differences 
at a 95\% confidence level. If differences were found, a Student's t-test with the Bonferroni posthoc analysis was used to determine what the differences were, at a 95\% confidence level.

\section{Text analysis for climate change skepticism}

A manual text analysis was conducted to categorize the news links and non-news links as skeptical or non-skeptical. This was accomplished by accessing each link and manually evaluating the link's content. A link was categorized as skeptical if any portion of the content insinuated that climate change is not occurring, that climate change is not anthropogenic, that climate change is not an important global issue, or that there is scientific debate regarding climate change. Any amount of skepticism provided (even if just a single quote from an interviewee to fulfill the news value of balance) is considered a distortion of reality and was labeled as skeptical. While balance is effective in many cases, the use of this news value in the reporting of climate change can be problematic (Boykoff, 2007) and the National NewsMedia Council (NNC) has stated that the news value of balance is not required by journalists who are writing about climate change because, "the great majority of science and expertise rests on one side of the issue" (NNC, 2016). If the link's content did not fall under the skeptical category, then it was categorized as non-skeptical.

\section{Social network analysis for climate change skepticism}

Users were categorized by the types of tweets they regularly shared. Categorizing users this way made it possible to see what type of information was highly retweeted and mentioned within the network. The users were placed into one of nine categories: 
Skeptical News Provider: a user with more than $50 \%$ of their posts being original posts and more than $50 \%$ of their links are to a skeptical news source;

Non-Skeptical News Provider: a user with more than 50\% of their posts being original posts and more than $50 \%$ of their links are to a non-skeptical news source;

Skeptical Non-News Provider: a user with more than 50\% of their posts being original posts and more than $50 \%$ of their links are to a skeptical non-news source;

Non-Skeptical Non-News Provider: a user with more than 50\% of their posts being original posts and more than $50 \%$ of their links are to a non-skeptical non-news source;

Skeptical News Amplifier: a user with more than 50\% of their posts being retweets and more than $50 \%$ of their links are to a skeptical news source;

Non-Skeptical News Amplifier: a user with more than 50\% of their tweets being retweets and more than $50 \%$ of their links are to a non-skeptical news source;

Skeptical Non-News Amplifier: a user with more than 50\% of their posts being retweets and more than $50 \%$ of their links are to a skeptical non-news source;

Non-Skeptical Non-News Amplifier: a user with more than 50\% of their posts being retweets and more than $50 \%$ of their links are to a non-skeptical non-news source;

Other: a user that did not fit into one of the categories above.

The total mean degree centrality was determined for each type of user outlined above. In order to compare the different user categories' mean degree centralities, an ANOVA test was completed to determine if there were differences at a 95\% confidence level. If differences were found, a Student's t-test with the Bonferroni post-hoc analysis was used to determine what the differences were, at a $95 \%$ confidence level. 


\section{Social network analysis for top ten users}

The ten users with the highest total degree centrality in the entire \#climatechange network of 99,989 tweets from Dec. 4th to Dec. 8th were categorized into the same nine classifications outlined above. The total mean degree centrality was calculated for each user category. Understanding these top ten users is potentially important; they provide a sample of the most central users in the network.

\section{Intercoder reliability}

A sample of 300 tweets from 46 users was recoded by a second researcher. The sample size exceeds the intercoder reliability guidelines set forward in Riffe et al. (2014). Cohen's Kappa was calculated as 0.85 , indicating that the categories can be reliably distinguished, independent of researcher (Wimmer \& Dominick, 1997).

\section{Results}

A total of 2,849 tweets from 368 Twitter users were characterized. There were 2,718 links embedded in these 2,849 tweets. Of these tweets, $58.3 \%$ were retweets.

The number of links per tweet ranged from zero (no link) to three. The majority of tweets (77.1\%) provided at least one link. Of these 2,718 links, 850 were considered faulty because they did not lead to a functional website. Another 702 links connected to a Twitter page or tweet and were not analyzed further because they did not directly share climate change information. These faulty links and other Twitter links were considered "non-functional" links. The remaining 1,166 links, representing $42.9 \%$ of all links, were labeled as "functional" links. These were selected for further analysis because they represent a source of potential information dissemination as well as 
a source of potential misinformation dissemination, as users may share links without providing context (Castillo et al., 2011; White, 2013). Even when users try to provide context, they are constrained by Twitter's capabilities, namely, that tweets have a 140-character limit, which creates a wealth of fragmented statements and a dearth of comprehensive understanding.

Users relied on sources such as environmental NGO websites, government websites, blogs, and scientific journals more than news sources: $58.8 \%$ of the functional links were nonnews sources while $41.2 \%$ were news sources (Figure 1). Interestingly, of the news links, $70.2 \%$ were mainstream, while $29.8 \%$ were alternative.

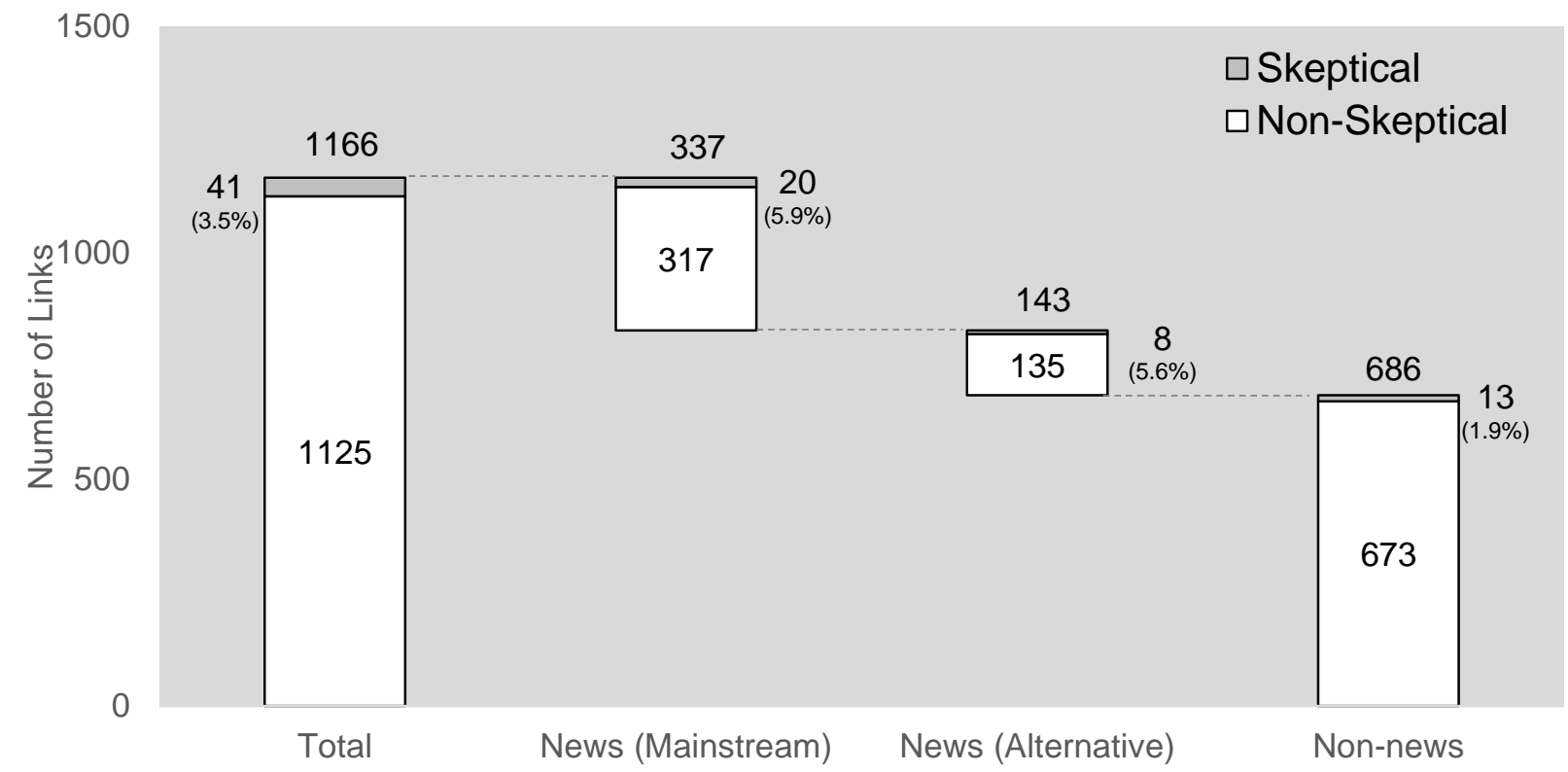

Figure 1 - Skeptical/Non-Skeptical summary of all News and Non-News links in sample.

The mean degree centrality for users that posted non-news links and news links was determined to be 38.0 and 14.6 respectively; after running an ANOVA test, the difference was not found to be statistically significant (significance assigned at $\alpha<0.05$ ). A more granular analysis (Figure 2) that disaggregates amplifiers and providers of information, suggests that non- 
news providers are more central than the other groups, as the mean degree centrality for users with this classification is 113.6 , while the mean degree centrality for news providers, news amplifiers, and non-news amplifiers is $16.8,13.0$, and 7.3 , respectively. The difference in means between non-news providers and non-news amplifiers is statistically significant (significance assigned at $\alpha<0.05)$. The difference between non-news providers and each of the other categories (news providers and news amplifiers) was not found to be statistically significant (significance assigned at $\alpha<0.05)$.
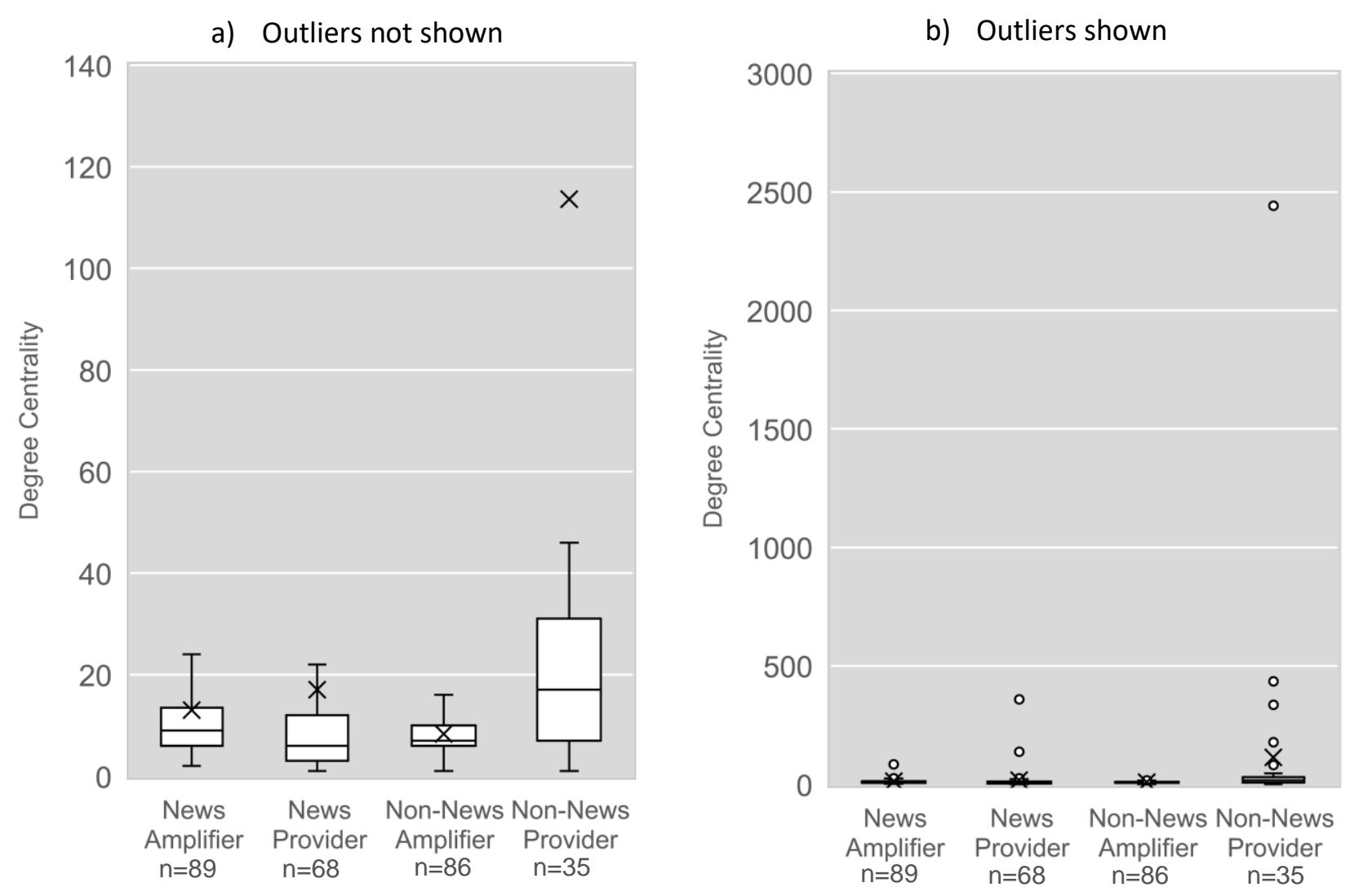

Figure 2 - Box plot of degree centrality for each user category. Of the 368 Twitter users, 90 fit into the Other category and are not depicted in this graph because the content of their tweets is undefined. The other 278 users are shown. All data are exhibited in both charts; however, outliers are not visually depicted in a). The ' $\mathrm{X}$ ' represents the mean, the horizontal line represents the median, upper and lower hinges represent the first and third quartiles, and whiskers extend from hinges to $1.5 *$ interquartile range. 
As seen in Figure 1, 3.5\% of all news and non-news links were defined as skeptical. Overall, $5.8 \%$ of all news links contained skeptical content while only $1.9 \%$ of all non-news links contained skeptical content. Mainstream news had the highest level of skepticism, with $5.9 \%$ of the total links being categorized as skeptical. This demonstrates that mainstream media links shared on Twitter are more likely to contain content that is skeptical of climate change science than non-news links, which may reflect the news value of balance, where news entities try to provide both perspectives on a topic even when there is a consensus on an issue (e.g. climate change).

In order to better understand how skeptical links were shared, the mean degree centrality was determined for users that posted skeptical links (18.1) and non-skeptical links (24.9). Using an ANOVA test, the difference between the means of the two group's degree centralities was not found to be statistically significant (significance assigned at $\alpha<0.05$ ). A more granular analysis revealed that users classified as non-skeptical non-news providers exhibited a higher mean degree centrality than both non-skeptical news amplifiers and non-skeptical non-news amplifiers; this was a statistically significant difference (significance assigned at $\alpha<0.05$ ) (Figure 3). Users classified as skeptical news amplifiers exhibited a higher mean degree centrality than nonskeptical news amplifiers and non-skeptical non-news amplifiers, with a statistically significant difference (significance assigned at $\alpha<0.05$ ). Users classified as non-skeptical news amplifiers exhibited a higher mean degree centrality than non-skeptical non-news amplifiers, with a statistically significant difference (significance assigned at $\alpha<0.05$ ). Taken together, these results suggest that two subgroups exhibit higher centrality in the network: non-skeptical non-news providers and skeptical news amplifiers. 


\section{a) Outliers not shown}

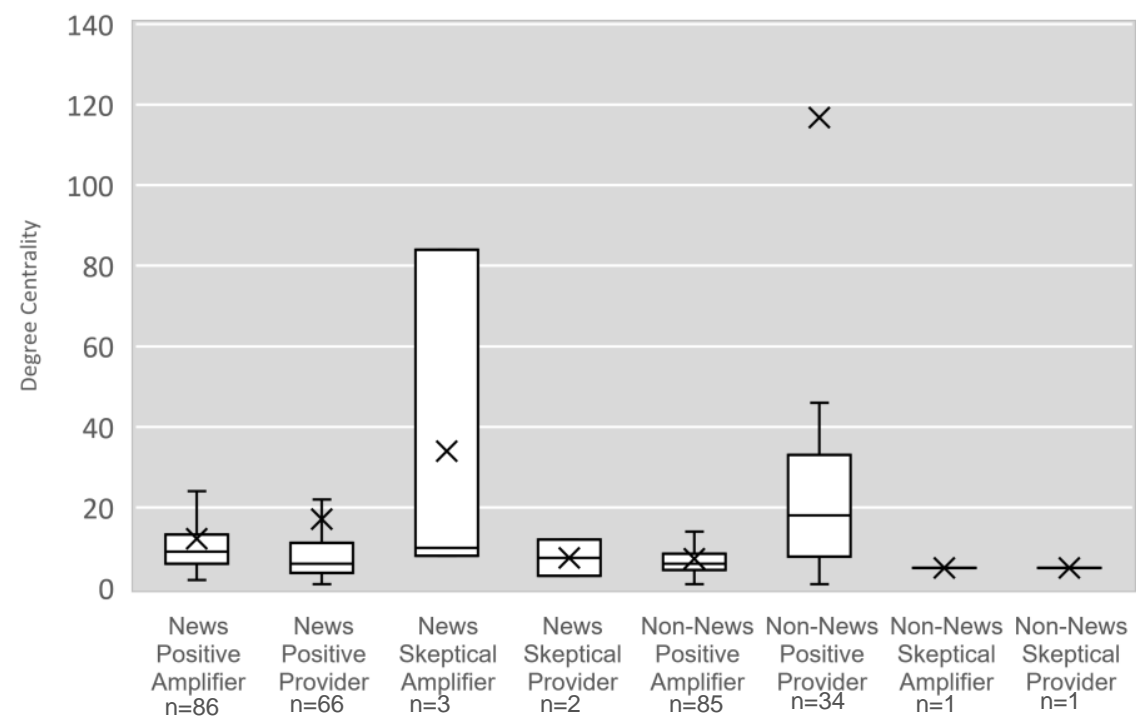

\section{b) Outliers shown}

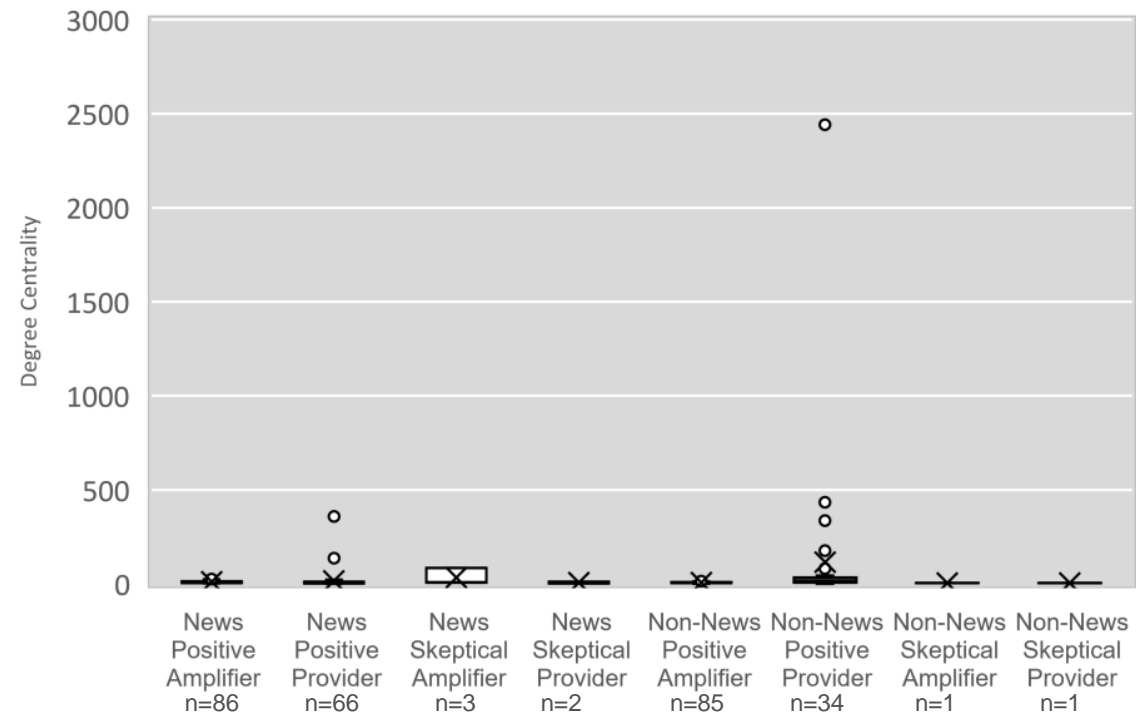

Figure 3 - Box plot of degree centrality for each user category. Of the 368 users, 88 cannot be suitably categorized using the framework developed in this research (categorized as Other) and are not depicted in this graph. The other 280 users are shown. All data are exhibited in both charts; however, outliers are not visually depicted in a). The ' $\mathrm{X}$ ' represents the mean, the horizontal line represents the median, upper and lower hinges represent the first and third quartiles, and whiskers extend from hinges to $1.5 *$ interquartile range. 
To better understand the extent to which outliers (e.g. users who exhibit unusually high degree centrality) influence the average degree centrality for each group, especially the nonskeptical non-news provider category, the ten users with the highest degree centralities in the entire \#climatechange network of 99,989 tweets from Dec. 4th to Dec. 8th were categorized (Figure 4). Two of the users from the top ten had been included in the original random sampling of 368 Twitter users. These ten users were organized by the same user categories as found in Figure 3.

The categorization of these users revealed that six of the "top ten users" were defined as non-skeptical non-news sources, one of the users was defined as a skeptical news source, and three were defined as other. This suggests that the mean degree centrality of non-skeptical nonnews users, as seen in Figure 4, is magnified by a small proportion of "key" users. The top ten users were almost entirely made up of different operations of the United Nations (UN); @UNICEF, @COP21@UNFCCC, @WHO, @UN, @UN_Spokesperson, and @UNDP.The predominance of UN accounts is likely related to the fact that COP21 was organized by the United Nations Framework Convention on Climate Change (UNFCCC). Thus, information channels were inundated with these official messages while the conference was proceeding, which would likely not be the case in other time periods. Further, users would expect these social media channels to display credible and relevant information related to the conference and would therefore follow these UN users. These UN users did, in fact, post content related to the conference. As a result, users would be more likely to share this UN content during this time period with the hashtag "\#climatechange". 


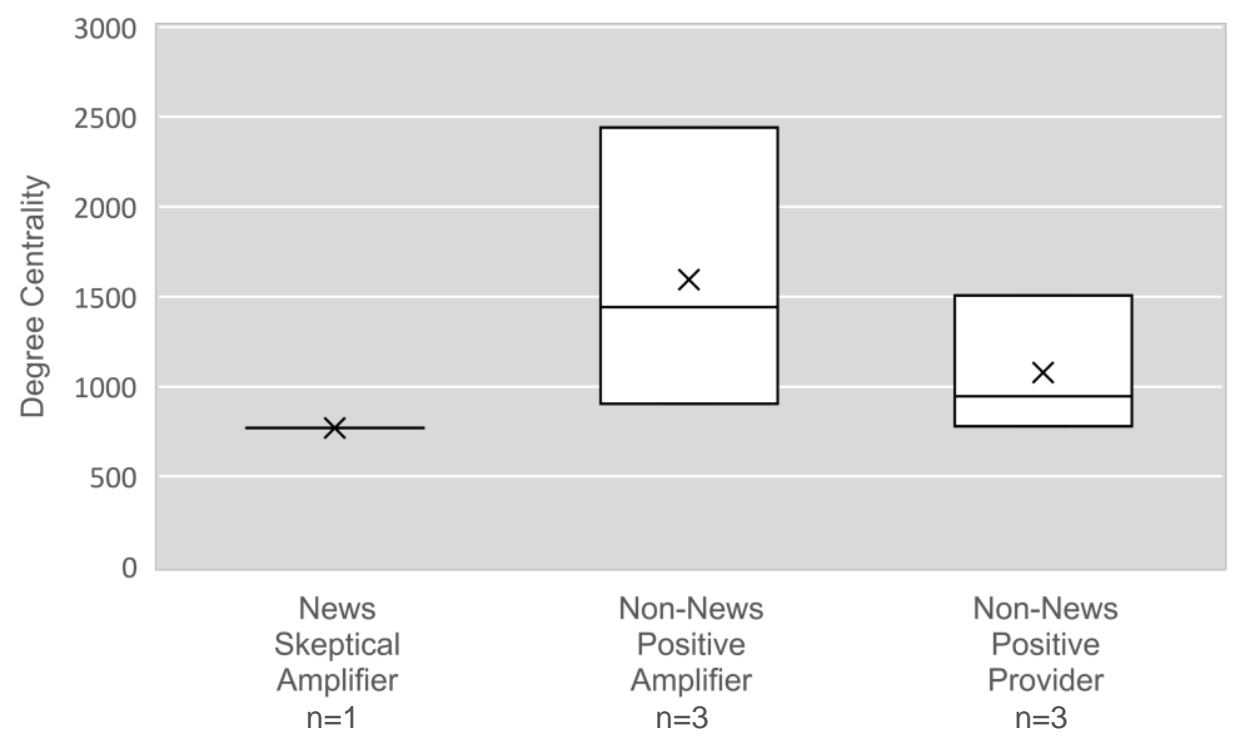

Figure 4 - Box plot of degree centrality for each user category for top ten users. Of the ten users, three cannot be suitably categorized using the framework developed in this research (categorized as Other) and are not depicted in this graph. The other seven users are shown.

\section{Discussion}

Two interesting results contribute to understanding how Twitter affects the dissemination of climate change information.

First, news links were more likely than non-news to contain content skeptical of climate change (5.8\% vs. $1.9 \%)$. Journalists often use balance, namely, the reporting both sides of an issue with equal attention, even if one side of the issue has achieved consensus among the experts in the field (Cox, 2012). The results presented here suggest that journalists continue to use this traditional norm in an era where they are aware that their content will be shared in a variety of social media channels. This is important because while there is scientific consensus that anthropogenic climate change is a serious, global issue that needs to be a priority for the public (Houghton et al., 2001; IPCC, 2014; Lorenzoni et al. 2007) journalists are providing some skeptical information that could create doubt among members of the public and either justify 
their skepticism of the phenomenon or lower their level concern for the issue. These findings support the research performed by Boykoff and Boykoff (2007), who demonstrated that media coverage of climate change was divergent from the IPCC dialogue. However, the present research suggests that this divergence is much less common than was exhibited in Boykoff and Boykoff's (2007) research. These findings are also aligned with literature that suggests that news values influence and impede accurate reporting of climate change science (Cox, 2012), contributing to informational bias and leading to content-deficient journalistic reporting of climate change issues (Anderson 2008; Boykoff \& Boykoff, 2007). Interestingly, mainstream news links were twice as abundant as alternative news links, while both types of links exhibited similar skepticism. The prevalence of mainstream news links suggests that this type of content, with its embedded balance news value, continues to be relied upon by the public. The similarity in skepticism between mainstream and alternative news suggests that alternative news sources may also adhere to the norm of balance that has been so well-documented in mainstream media. Taken together, the relatively high degree centrality of skeptical news amplifiers suggest that this journalistic balance increases the availability of climate change misinformation.

Second, non-news articles were less likely to contain content that was skeptical of climate change, as the authors were not bound by the traditional journalist value of balance. These 'less balanced' articles were often shared by users (non-skeptical non-news providers), who exhibited high degree centrality. Since these accounts were maintained by organizations like the UN, the public was likely more prone to retweet their content because they represent authority figures (e.g. the UN coordinated this conference). This complements the literature that suggests there are a relatively small number of influential people on Twitter (Gaffney, 2010; White, 2013). Taken together, these findings suggest that social media enables organizations that are not bound by 
journalistic norms to share content that is widely circulated. In the context of climate change, this ability to avoid the norm of balanced reporting enables discussions that are more aligned with the scientific community's understanding of climate change. The high total degree centrality of many of these users goes counter to the literature that suggests that people rely heavily on news sources (Arlt et al., 2011; Schäfer, 2012a; Schäfer \& Sclichting, 2014; Stamm et al., 2000). 


\section{Conclusion}

This research provides insight into how climate change information is disseminated on Twitter. News links are more likely than non-news to contain content that is skeptical of climate change, as journalists rely on established press rules, particularly, balance. The relatively high degree centrality of users who predominantly share these types of articles (skeptical news amplifiers) suggests that this balance may increase the availability of climate change misinformation to the public. This is in close agreement with literature that suggests that news values influence and impede accurate reporting of climate change science (Cox, 2012), thereby contributing to informational bias and leading to content-deficient journalistic reporting of climate change issues (Anderson 2008; Boykoff \& Boykoff, 2007). Second, the relatively high degree centrality of users who predominantly post original non-skeptical non-news tweets suggests that audiences on Twitter do not rely as heavily on news sources as previous literature has shown.

\subsection{Limitations}

Limitations related to the statistical analyses and data collection methodology should be considered when interpreting the results presented in this paper. With respect to the statistical analyses, a sizeable portion $(24 \%)$ of the users in the study could not be classified using the eight categories developed in this framework. Consequently, this analysis excludes users who exhibit ambivalent behaviors (e.g. post original content and retweet at the same rate). Furthermore, performing robust statistical analysis was impossible in many instances given the small sample size of some user categories, the high variance in degree centrality for some user categories, and the presence of outliers (highly connected users). Thus, observing differences between user 
categories was likely incomplete, as many differences could not be detected given the nature of the data. In regards to the data collection methodology, all tweets were collected in a period of a few days during the COP21 conference. As a result, these tweets do not represent the general discussion of climate change on Twitter throughout the year. Instead, these tweets are from users who are likely aware of this climate change conference and are therefore more likely to have a knowledge of climate change science. Furthermore, information channels during this conference were inundated with official messages from the UN, which would likely not be the case in other time periods. Moreover, this data collection demonstrates only the content that users choose to share, which may not reflect the underlying content that is available in the traditional media channels with respect to skepticism or non-skepticism. For example, a user could choose to share content because of additional factors related to the traditional news source (e.g. availability of content, accessibility of writing style, length of article) rather than content (skepticism vs. nonskepticism). The methodology presented in this paper does not attempt to identify and measure the influence of these exogenous variables.

\subsection{Directions for Future Research}

This study provides an initial look at what climate change information is available to the public and how it is shared among users. There are two important questions raised by the findings in this study that the present author recommends as avenues for future research.

First, how is climate change information communicated in the body of tweets? The present research focused on links shared within tweets and did not address the climate change statements made directly by the users. Reader comments on climate change coverage contribute

to the diverse, complex, and disputed field, and thereby have the potential to shape thinking and 
public discourse around this environmental phenomenon (Koteyko et al., 2013). Therefore, it is imperative that these statements are analyzed in order to elucidate the users' direct role in communicating climate change information. A study using a similar framework as the present research (characterize tweets and then analyze sharing patterns) could be completed with a focus on user statements rather than on links shared by the users.

Second, is it possible for people to be persuaded by the climate change information on social media or do echo chambers preclude this? While the present research addressed the quantity and sharing patterns of climate change information on Twitter, it did not extend to understanding how this information impacts the users' knowledge of the phenomenon. It is important to understand how climate change information on Twitter is impacting the users' understandings and beliefs about climate change in order to accurately communicate with them. If echo chambers are preventing people from getting factual information, solutions may need to be developed. To study this, two objectives would need to be pursued concurrently: a) evaluate whether users regularly view tweets that they disagree with (e.g. does a climate change skeptic ever read non-skeptical articles?), and b) measure if any of these users change their behaviour on social media (e.g. does a skeptic ever stop posting skeptical content?).

Expanding the breadth of research to look at time periods other than during the 2015 United Nations Climate Change Conference and expanding the depth of research to look at look at a comparison of online and offline networks (i.e. social media vs traditional media) (Sullivan \& Xie, 2009; White, 2013) would also be reasonable. 


\section{APPENDICES}

\section{Appendix A: Coding Instructions}

Read through all instructions before beginning. Overall, the purpose of this experiment is to determine the quantity and type of links provided by Twitter users who are discussing climate change.

\section{Step 1.}

Filter all tweets to determine if they are an Original post or a Retweeted (RT) post. If a tweet is an Original, place a 1 in the Original category and a 0 in the RT category. If a tweet is a RT, place a 1 in the RT category and a 0 in the Original category.

Definition: A tweet that has 'RT' included in the post (usually at the beginning) will be considered a retweeted post. A tweet that does not include the phrase 'RT' will be considered an original post.

\section{Example of Original tweets:}

- Hey \#RedDeer \#YQF, \#WhatWouldYouSayInParis? Submit your Viewpoint here: https://t.co/0KMpTSatKI ... \#viewpointsab \#cop21 \#climatechange

- Public debate muddies the waters in \#climatechange education https://t.co/IVoLEz2CJT \#climate \#AGW \#STEM

- @ @ POTUS I donl't think the coordinated attacks in \#Paris has a thing 2 do w \#ClimateChange. Defend America \&amp; our allies! Get off the golf crs!

\section{Example of RT tweets:}

- RT @Greenpeace: A major Greenland glacier is collapsing. And itâ€(M $€_{\mathrm{S}}$ only just the beginning. \#climatechange https://t.co/6ohmNXJOii https://tâ€!

- RT @ HayesGrier: Be sure to watch \#24hoursofreality itl's time to make a change. Check it out on @ go90 \#climatechange

- RT @CNNMoney: Over 100 million people could be pushed into poverty due to \#climatechange https://t.co/j8xE9eAC4O via @AOL https://t.co/OC4Aâ€!

\section{Step 2.}

Filter all tweets for links. If a tweet contains zero links, write 0 . If a tweet contains one or more links, write the number of links i.e. 1, 2, 3, etc.

Definition: A link within a tweet is denoted by "https". You must go through to determine the number and type (see Steps 3 through 5) of link(s) in the tweets.

\section{Example of tweets with link(s):}

- RT@SomersetBean: Closed to citizens, open to lobbyistsâ€’''Lobby Planet Parisl' guide exposes "Corporate \#COP21": https://t.co/WTV2IdEkvo httpâ $\epsilon_{\mid}$

- RT @ cmkshama: We canl't rely on capitalist world leaders to end \#ClimateChange. That task is up to us: https://t.co/LZS0YBGdJA \#COP21 
- RT @ ClimateNewsCA: Climate extremists pretend to die from 400ppm CO2. https://t.co/j4aeo8en5U\#ClimateChange \#GlobalWarming \#COP21

- RT @IFADnews: Support \#IFADI's Make the Change petition https://t.co/2LfLL8u53B \#adaptnow \#COP21 https://t.co/NbnEJRHdko

\section{Example of tweets without link(s):}

- $\quad$ RT @ HayesGrier: Be sure to watch \#24hoursofreality itl's time to make a change. Check it out on @ go90 \#climatechange

- \#soil has major role in \#climatechange; needs more \#research. Must dig out the @jrcl's \#soil_atlas

- @ andyburnhammp Did you go to the House today to discuss climate change? Your name is not listed. \#climatechange \#ActOnClimate

\section{Step 3.}

*NOTE: steps 3-5 need to be done simultaneously so each tweet can be placed into the correct category (as seen in the sample table). I have separated these into three steps in the instructions to provide a clear understanding of what is required.

**Some tweets will have more than one link. You must repeat steps 3-5 for all links.

Determine if the link leads to a news source, a non-news source, another Twitter account/page, or if it is a faulty link by opening the link. Open and code all links in every tweet. Write the number of links that fall into each category per tweet i.e. $0,1,2$, etc.

Definition News Source: An article or webpage for any newspaper, magazine, television broadcaster, radio broadcaster, or news agency (wire service). If you are unsure just by looking at the article/page that the link brought you to, try to visit the website "About" or "Home" pages to get a better understanding of how they describe themselves. If their self-proclaimed main purpose is as a news source, then it will be considered a link to a news source. If this information is not provided on their website then try finding alternative sources that describe the organization's purpose. If you are unable to find this information after a reasonable search (no more than two minutes), then the source will be considered non-news.

\section{Examples of tweets with links to news sources:}

- I'In The Balancel' on the role of business \&amp; finance to counter the climate threat \#COP21 @BBCworldservice https://t.co/zts50o7ZIo h/t @WBCSD (leads to the $\mathrm{BBC})$

- A proud \#feminist would protect all women!@JustinTrudeau @ Chatelaine @ElizabethMay \#COP21 \#CBCNN \#OpCanary https://t.co/9bOAiwYZzD (leads to HuffPost Business)

- RT @ yesmagazine: Meet 5 Everyday People Journaling from the Paris Climate Talks https://t.co/iUAspbJaUg \#ParisDiaries \#COP21 https://t.co/qâ€! (leads to Yes! Magazine)

Definition Non-News Source: Any webpage that is not considered a news source, is not another tweet/Twitter page, or a faulty link. This could be a blog post/blog, a government post/website, a 
NGO post/website, a science organization's post/website, a petition, a Youtube video, a Vine, etc. If the article/page is linked to an organization/company/etc. that does not describe their main purpose as a news agent, then they will be considered non-news (even if the post is under a subsection called news).

\section{Example of tweets with links to non-news sources:}

- $\quad$ RT @NASA: Admin. Bolden: Wel're "uniquely positioned to study our home planet." Read his blog: https://t.co/0Io9f92EE3 \#COP21 https://t.co/Kâ€।(leads to blog on NASA website)

- $\quad$ Droughts, floods, storms \&amp; other disasters triggered by \#climatechange pose growing threat to \#foodsecurity https://t.co/V7Otr5knfO \#cop21â€ (leads to a news story by The Food and Agriculture Organization of the United Nations - an agency of the United Nations which therefore does not count as news)

- $\quad$ Sign the petition to tell big oil giant @Total to keep its lobbyists out of the \#Paristalks \#cop21 \#climatetalks https://t.co/aIeH0czBoy (leads to SumOfUs petition)

- RT @WWF: Colourful reefs are turning white... Why? \#Climatechange. We need action now. \#COP21: https://t.co/Tmk1n32kbI https://t.co/xP3fA7Wâ€। (leads to WWF page)

Definition Another Twitter Account/Post: Some links lead to another Twitter user's page or post. If the link takes you to a page that begins with "https://twitter" or "https://t.co" than it will be considered another Twitter Account/Post.

\section{Examples of tweets that link to another tweet/Twitter page:}

- $\quad$ RT @ElizabethMay: My interview with CBC earlier today. One week to go. \#COP21 \#GPC https://t.co/zZ6rnYmimL (leads to a CBC tweet)

- $\quad$ RT @RSPBScience: GUEST BLOG \#wildlife on the move due to \#climatechange @Rich_B_Bradbury https://t.co/qnfYOR4nRL https://t.co/byvbOKs52k (the second link leads to a RSPBScience tweet but the first one leads to a non-news source)

- RT @ shannon_h: We are launching this new series-- let us know how you are seeing and talking about \#climatechange https://t.co/DsNDhjegXc (leads to a WBEZ tweet)

Definition Faulty Link: Does not lead to any webpage due to a broken or faulty link. Usually has a message such as, "page not found".

\section{Examples of tweets with faulty links:}

- RT @ineeshadvs: Inspiring words from @ LeoDiCaprio - calls on 1,000 mayors to \#go100percent \#Cities4Climate \#COP21ÂA \#100isnos https://t.co/6â€! (leads to Twitter website with message, "Sorry, that page does not exist!")

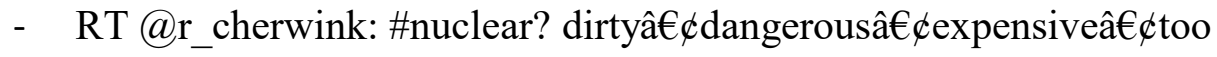
slow!https://t.co/XG4JmjFfEn https://t.co/Sf4q2XW2fv \#BustTheMyth \#COP21 https:/â€। (the first link leads to a page that says, "Uh oh, this campaign is not ready yet $=()$

Step 4. (Skip for non-news, other Twitter account, faulty links) 
Determine if the news source links lead to a news source that is Mainstream or Alternative. Write the number of Mainstream and Alternative links in the corresponding category for all tweets that contain at least one news source link i.e. 1, 2, etc.

Definition Alternative News Source: Alternative news is any news entity that does not appear on the Pew list (print list and keep on hand) of top 50 online news entities, exists only online, and/or describes itself as independent/alternative media (e.g. Indymedia, Free Speech TV, The Raw Story).

\section{Example of tweets with alternative news links:}

- Historically \#Exxon \&amp; \#kochbrothers amply funded \#climatechange denial:https://t.co/Z1IH5uzxPa https://t.co/JAR65D0gv6 (leads to an article from the Wall Street Hedge, a small online news entity)

- @ @kgrandia: 5 Things To Pay Attention to at the Paris Climate Change Conference \#cop21 \#climatechange https://t.co/Lg115safli (leads to the National Observer, a new, online, Canadian news site)

- Making the moral case on \#climatechange ahead of the \#ParisSummit. https://t.co/w1G6qbaqWt via \#US_Conversation (leads to The Conversation, a website described as an independent source of news)

Definition Mainstream News Source: Mainstream media is any news entity that does not fall under 'Alternative News Source'. This includes any news entity that appears on Pew's list of the top 50 online news entities, as well as any news entity that does not appear on the list but is established outside of the internet (e.g. The Toronto Star, National Geographic, Al Jazeera).

\section{Examples of tweets with mainstream news links:}

- RT @WFP_Media: Heading into \#COP21, @UNICEF warns \#climatechange will hit children hardest, via@AJEnglishhttps://t.co/DHfy8qQXdF https://â€। (While Al Jazeera is not on the list of top 50 digital news entities, it is one of the world's largest news organizations and is well-established outside of the internet)

- \#ClimateChange \#CC Canadaâ€ $€^{\mathbf{T M}_{\mathrm{S}}}$ New Leadership Reverses Course on Climate Change: New York Times:... https://t.co/l6dDwOeSuP \#UniteBlue \#Tcot (links to New York Times article, which is on the top 50 list)

- RT @ResilienceKenya: Climate Change Is Here - National Geographic Magazine: https://t.co/zKCqmRFTYd via@@NatGeo \#ClimateChange \#Climate \#Kâ€!(leads to National Geographic, which is not on the list but is a magazine that has been around since 1888 and has a global circulation of 6.8 million per month)

\section{Step 5. (Skip for other Twitter account, faulty links)}

Determine if the links to all news sources and the links to all non-news sources are skeptical of climate change or not skeptical of climate change.

Skeptical Definition: If any portion of the article, blog post, or information on the page states or provides a statement from another source (without refuting it) that climate change is not occurring, that climate change is not anthropogenic, that climate change is not an important, world issue, or that there is not a scientific consensus on climate change, then it will be labeled as skeptical. There is scientific consensus that climate change is real, is anthropogenic, and is a 
major global issue, so any amount of skepticism provided (even if just one quote from an interviewee) is a distortion of reality and therefore the article is Skeptical.

\section{Example of tweets that have links to skeptical news sources:}

- RT @Drudge_Report_:REP: \#NOAA I'\#ClimateChangel' science fiction...Agency ignores \#satellite data... https://t.co/2WMiso7ZRc (leads to a Washington Times article that says, "Atmospheric satellite data, considered by many to be the most objective, has clearly showed no warming for the past two decades. This fact is well documented, but has been embarrassing for an administration determined to push through costly environmental regulations")

\section{Example of tweets that have links to skeptical non-news sources:}

- @ @ariabilityBlog The massaged data falsely shows warming. No warming for 20 years https://t.co/syjAZWtxhx\#AgwHoax \#COP21 \#ClimateChange (leads to a blog that says global warming is not occurring and that climate change is a hoax)

Non-Skeptical Definition: If the article, blog post, or information on the page does not fall under 'Skeptical', then it is considered Non-Skeptical.

Example of tweets that have links to non-skeptical climate change news sources:

- RT @Greenpeace: Children in poverty will suffer the most from \#climatechange, says @UNICEF report https://t.co/vS6Req6vpw https://t.co/Hlcwâ $€_{\text {। }}^{\prime}$ (leads to PACNEWS which is a news agency/wire service that has a newspaper, television, and radio so this would be a NEWS SOURCE/MAINSTREAM/NON-SKEPTICAL)

- RT @greenpeaceusa: Why are some Americans still skeptical about \#climatechange? Here's one big reason: https://t.co/29GjsrvBeK https://t.coâ€। (while The Washington Post is discussing climate change skepticism, the article remains non-skeptical)

Example of tweets that have links to non-skeptical climate change non-news sources:

- Citizen Journalist: \#climatechange \#globalwarming \#EastAntarctica \#TottenGlacier If all of East Antarctic Ice Sheet. https://t.co/xelFrPPK8u

- \#Obama \#climatechange https://t.co/Oz6I8b6HjL https://t.co/DNcfV9u665 (The first link leads to a non-skeptical climate change article on The World Bank's website. The second link leads to another Twitter account so it would fall under that category). 


\section{Appendix B: Pew List of Top 50 Digital News Entities}

Retrieved from: http://libguides.wlu.edu/c.php?g=357505\&p=2412837\#s-lg-box-7395118

\begin{tabular}{|l|l|l|}
\hline 1. Yahoo-ABC News Network & 20. Los Angeles Times & 40. NJ.com \\
\hline 2. CNN & 21. New York Post & 41. Independent \\
\hline 3. NBC News Digital & 22. Time & 42. Detroit Free Press \\
\hline 4. Huffington Post & 23. Mashable & 43. Boston Globe \\
\hline 5. CBS News & 24. SFGate & 44. Atlantic \\
\hline 6. USAToday & 25. Slate & 45. MLive \\
\hline 7. BuzzFeed & 26. Upworthy & 46. Engadget \\
\hline 8. New York Times & 27. TheBlaze & 47. TechCrunch \\
\hline 9. Fox News Digital Network & 28. Telegraph & 48. Boston.com \\
\hline 10. Daily Mail & 29. U.S. News & 49. AL.com \\
\hline 11. Washington Post & 30. Vice & 50. Dallas Morning News \\
\hline 12. Bleacher Report & 31. Chron & \\
\hline 12. Business Insider & 32. Gawker & \\
\hline 13. Elite Daily & 33. Examiner & \\
\hline 14. BBC & 34. Vox & \\
\hline 15. CNET & 35. Chicago Tribune & \\
\hline 16. Guardian & 36. Daily Beast & \\
\hline 17. MSN News & 37. Salon & \\
\hline 18. NPR & 38. Mic & \\
\hline 19. New York Daily News & 39. Mirror Online & \\
\hline
\end{tabular}




\section{Appendix C: Intercoder Analysis}

Table 1 - Summary of intercoder analysis using Cohen's Kappa. Prepared using same method as described in Sun (2011). The result of 85\% suggests that the categorizations are reproducible (Wimmer \& Dominick, 1997).

\begin{tabular}{|c|c|c|c|c|c|c|c|}
\hline & $\begin{array}{c}\text { Non- } \\
\text { Skeptical } \\
\text { News } \\
\text { Amplifier } \\
\end{array}$ & $\begin{array}{c}\text { Non- } \\
\text { Skeptical } \\
\text { News } \\
\text { Provider }\end{array}$ & $\begin{array}{c}\text { Non- } \\
\text { Skeptical } \\
\text { Non-News } \\
\text { Amplifier }\end{array}$ & $\begin{array}{c}\text { Non- } \\
\text { Skeptical } \\
\text { Non-News } \\
\text { Provider }\end{array}$ & $\begin{array}{c}\text { Skeptical } \\
\text { Non-News } \\
\text { Amplifier }\end{array}$ & Undefined & TOTAL \\
\hline Non-Skeptical News Amplifier & 5 & & 3 & & & & 8 \\
\hline Non-Skeptical News Provider & & 4 & & 1 & & & 5 \\
\hline Non-Skeptical Non-News Amplifier & & & 16 & & & & 16 \\
\hline Non-Skeptical Non-News Provider & & & & 4 & & & 4 \\
\hline Skeptical Non-News Amplifier & & & & & 1 & & 1 \\
\hline Undefined & & & 1 & & & 11 & 12 \\
\hline TOTAL & 5 & 4 & 20 & 5 & 1 & 11 & 46 \\
\hline Predicted chance agreements & 0.87 & 0.43 & 7 & 0.4 & 0.02 & 2.9 & \\
\hline Total \# agreements & 41 & & & & & & \\
\hline Total \# chance agreements & 11.59 & & & & & & \\
\hline Total \# subjects & 46 & & & & & & \\
\hline Cohen's Kappa & $85 \%$ & & & & & & \\
\hline
\end{tabular}




\section{REFERENCES}

Ahmad, A. N. 2010. Is Twitter a useful tool for journalists? Journal of Media Practice, 11(2), 145-155.

Allan, S. 2010. News culture. New York, NY, Open University Press.

Anderson, A. 2008. Media, politics and climate change: Towards a new research agenda. Sociology Compass, 3(2), 166-182.

Arlt, D., Hoppe, I., \& Wolling, J. 2011. Climate change and media usage: Effects on problem awareness and behavioural intentions. International Communication Gazette, 73(1-2), 45-63.

Bajpai, K. \& Jaiswal, A. 2011. A framework for analyzing collective action events on Twitter. Proceedings from The eight international ISCRAM conference. Lisbon, Portugal.

Barberá, P., Jost, J. T., Nagler, J., Tucker, J. A., \& Bonneau, R. 2015. Tweeting from left to right is online political communication more than an echo chamber? Psychological science, 1-12.

BBC. 2015, July, 2. BBC to cut more than 1,000 jobs. Retrieved from: http://www.bbc.com/news/entertainment-arts-33363225

BBC. 2016. About BBC news: The BBC takes to the airwaves. Retrieved from: http://news.bbc.co.uk/aboutbbcnews/spl/hi/history/noflash/html/1920s.stm.

Bimber, B., \& Davis, R. 2003. Campaigning online: The Internet in U.S. elections. New York, NY, Oxford University Press.

Boyd, D., Golder, S., \& Lotan, G. 2010. Tweet, tweet, retweet: Conversational aspects of retweeting on Twitter. Proceedings from The forty-third international HICSS conference. Hawaii, United States.

Boykoff, T.M. 2007. Flogging a dead norm? Newspaper coverage of anthropogenic climate change in the Unites States and United Kingdom from 2003 to 2006. Area, 39(4), 470-481.

Boykoff, T. M. \& Boykoff, M. J. 2007. Climate change and journalistic norms: A case-study of US mass-media coverage. Geoforum, 38, 1190-1204.

Bruns, A. \& Burgess, J. 2012. Researching news discussion on Twitter. Journalism Studies, 13(5-6), 801-814.

Carvalho, A., \& Burgess, J. 2005. Cultural circuits of climate change in UK broadsheet newspapers, 1985-2003. Risk analysis, 25(6), 1457-1469.

Castillo, C., Mendoza, M., \& Poblete, B. 2011. Information credibility on Twitter. Proceedings from The twentieth international world wide web conference.

Chaffey, D. 2016. Global social media research summary 2016. Smart Insights. Retrieved from: http://www.smartinsights.com/social-media-marketing/social-media-strategy/new-global-socialmedia-research/. 
Chew, C., \& Eysenbach, G. 2010. Pandemics in the age of Twitter: content analysis of tweets during the 2009 H1N1 outbreak. PloS one, 5(11).

Choi, S. 2014. Flow, diversity, form, and influence of political talk in social-media-based public forums. Human Communication Research, 40, 209-237.

Clarke, A. 2012. "Open Dialogue" and the government of Canada's use of social media: Bureaucratic barriers to democratic engagement in the digital age. Proceedings from The Canadian political science association annual conference. Alberta, Canada.

Cohen, B. 1963. The press and foreign policy. Princeton, NJ, Princeton University Press.

Colleoni, E., Rozza, A., \& Arvidsson, A. 2014. Echo chamber or public sphere? Predicting political orientation and measuring political homophily in Twitter using big data. Journal of Communication, 64(2), 317-332.

Cox, R. 2012. Environmental communication and the public sphere. Thousand Oaks, CA, SAGE Publications.

Dahlgren, P. 1996. Media logic in cyberspace: repositioning journalism and its publics. Javnost-The Public, 3, 59-72.

Davenport, C. \& Harris, G. 2015, November, 30. Citing urgency, world leaders converge on France for climate talks. The New York Times. Retrieved from:

http://www.nytimes.com/2015/12/01/world/europe/obama-climate-conference-cop21.html?_r=0

Davis, R. 1999. The web of politics: The Internet's impact on the American political system. New York, NY, Oxford University Press.

Diani, M. 1995. Green networks: A structural analysis of the Italian environmental movement. Edinburgh, UK, Edinburgh University Press.

Diani, M. 2002. Network Analysis. In Klandermans, B. \& Staggenborg, S. (Eds.), Methods of Social Movement Research (173-200). Minneapolis, MN, University of Minnesota Press.

Downey, G.J. 2013. Telegraph messenger boys: labor, technology, and geography 1850-1950. New York, NY, Routledge.

Dunlap, R. E., \& Saad, L. 2001. Only one in four Americans are anxious about the environment. Gallup. Retrieved from: http://www.gallup.com/poll/releases/pr010416.asp.

European Commission. 2016. Paris Agreement. Climate Action. Retrieved from: http://ec.europa.eu/clima/policies/international/negotiations/paris/index_en.htm.

Farhi, P. 2009. The Twitter explosion. American Journalism Review, 31(3), 26-31.

Filloux, F. 2012, January, 8. How to make money from digital news. The Guardian. Retrieved from: http://www.theguardian.com/technology/2012/jan/18/make-money-from-digital-news.

Friend, D. 2015, November, 6. Bell Media plans to cut 380 jobs in Toronto and Montreal. The Canadian Press. Retrieved from: http://www.thestar.com/business/2015/11/06/bell-media-plansto-cut-380-jobs-in-toronto.html. 
Gaffney, D. 2010. \#iranElection: Quantifying online activism. Proceedings from The web science conference. North Carolina, United States.

Galston, W. A. 2003. If political fragmentation is the problem, is the Internet the solution? In D. M. Anderson \& M. Cornfield (Eds.), The civic web: Online politics and Democratic values (35-44). Lanham, MD, Rowman \& Littlefield.

Galtung, J. \& M. Ruge. 1965. The structure of foreign news. Journal of Peace Research, 2, 6491.

Greenhow, B. Y. C., \& Reifman, J. 2009. Engaging youth in social media: Is Facebook the new media format? Neiman Reports, 63(3), 53-55.

Grefe, Dick. 2015. Top 50 online news entities. Washington and Lee University. Lexington, VA. Retrieved from: http://libguides.wlu.edu/c.php?g=357505\&p=2412837\#s-lg-box-7395118.

Grosseck, G. 2009. To use or not to use web 2.0 in higher education? Procedia-Social and Behavioral Sciences, 1(1), 478-482.

Gruzd, A. \& Roy, J. 2014. Investigating political polarization on Twitter: A Canadian perspective. Policy and Internet, 6(1), 28-45.

Hamed, A.A., Ayer, A.A., Clark, E.M., Irons, E.A., Taylor, G.T., \& Zia, A. 2015. Measuring climate change on Twitter using Google's algorithm: Perception and events. International Journal od Web Information Systems, 11(4), 527-544.

Hart, A. 2014, October, 20. CNN Host Brian Stelter addresses major CNN layoffs. The Huffington Post. Retrieved from: http://www.huffingtonpost.com/2014/10/19/cnn-host-cnnlayoffs_n_6012132.html.

Hermida, A. 2010. Twittering the news: The emergence of ambient journalism. Journalism Practice, 4(3), 297-308.

Herrmann, S. 2009, December, 4. Mumbai, Twitter and live updates. BBC. Retrieved from: http://www.bbc.co.uk/blogs/theeditors/2008/12/theres_been_discussion_see_eg.html.

Houghton, J. T., Ding, Y. D. J. G., Griggs, D. J., Noguer, M., van der Linden, P. J., Dai, X., ... \& Johnson, C. A. 2001. Climate change 2001: the scientific basis. Cambridge, UK, Press Syndicate of the University of Cambridge.

Huurderman, A.A. 2003. The worldwide history of telecommunications. Hoboken, NJ, John Wiley \& Sons.

IPCC. 2014. Climate change 2014 synthesis report: Summary for policymakers. IPCC Fifth Assessment Report. Retrieved from: http://www.ipcc.ch/pdf/assessmentreport/ar5/syr/AR5_SYR_FINAL_SPM.pdf.

Jeffries, A. 2014, February, 14. You're not going to red this but you'll probably share it anyway. The Verge. Retrieved from: http://www.theverge.com/2014/2/14/5411934/youre-not-going-toread-this. 
Jin, F., Wang, W., Zhao, L., Dougherty, E., Cao, Y., Lu, C. T., \& Ramakrishnan, N. 2014. Misinformation propagation in the age of Twitter. Computer, 12, 90-94.

Jones, P., Cox, R., Daniel \& Navarro-Rivera, J. 2014. Climate change, environmental policy, and science: Religion, values, and climate change survey. Public Religion Research Institute. Retrieved from: http://publicreligion.org/site/wp-content/uploads/2014/11/2014-ClimateChange-FINAL1.pdf.

Kaplan A. M. \& Haenlein M. 2010. Users of the world, unite! The challenges and opportunities of social media. Business Horizons, 53(1), 61.

Keller, A. C. 2009. Science in environmental policy. The politics of objective advice. Cambridge, MA, MIT Press.

Kietzmann, J. H., Hermkens, K., McCarthy, I. P., \& Silvestre, B. S. 2011. Social media? Get serious! Understanding the functional building blocks of social media. Business Horizons, 54(3), 241-251.

Koteyko, N., Jaspal, R., \& Nerlich, B. 2013. Climate change and 'climategate' in online reader comments: A mixed methods study. The Geographical Journal, 179(1), 74-86.

Kwak, H., Lee, C., Park, H., \& Moon, S. 2010. What is Twitter, a social network or news media? Proceedings from The nineteenth international world wide web conference.

Leiserowitz, A., Smith, N. \& Marlon, J.R. 2010. Americans' knowledge of climate change. Yale Project on Climate Change Communication. Yale University. New Haven, CT. Retrieved from: http://environment.yale.edu/climate/files/ClimateChangeKnowledge2010.pdf

Lorenzoni, I., Nicholson-Cole, S., \& Whitmarsh, L. 2007. Barriers perceived to engaging with climate change among the UK public and their policy implications. Global Environmental Change, 17(3-4), 445-459.

Lotan, G., Graeff, E., Ananny, M., Gaffney, D., Pearce, I. \& Boyd, d. 2011. The revolutions were tweeted: The information flows during the 2011 Tunisian and Egyptian revolutions. International Journal of Communication, 5, 31.

Lovejoy, K. \& Saxton, G.D. 2012. Information, Community and Action: How nonprofit organizations use social media. Journal of Computer Mediated Communication, 17, 337-353.

Luedecke, G., McAllister, L., Nacu-Schmidt, A., Wang, X., Andrews, K., Boykoff, M., Daly, M., \& Gifford, L. 2015. United States coverage of climate change or global warming, 20042015. Center for Science and Technology Policy Research, Cooperative Institute for Research in Environmental Sciences. University of Colorado. Boulder, CO. Retrieved from: http://sciencepolicy.colorado.edu/media_coverage.

Macnamara, J. 2010. The 21st century media (r) evolution: Emergent communication practices. New York, NY, Peter Lang.

McCombs, M. E., \& Shaw, D. L. 1972. The agenda-setting function of mass media. Public Opinion Quarterly, 36(2), 176-187.

Meyer, P. 2008. The elite newspaper of the future. American Journalism Review, 30(5), 32-35. 
Morozov, E. 2009, April, 25. Swine flu: Twitter's power to misinform. Foreign Policy. Retrieved from: http://foreignpolicy.com/2009/04/25/swine-flu-twitters-power-to-misinform/.

Moser, C. S. 2010. Communicating climate change: history, challenges, process and future directions. WIREs Climate Change, 1, 31-53.

Murthy, D. 2013. Twitter: Digital media and society series. Bodmin, UK, Polity Press.

Mutz, D. C., \& Martin, P. S. 2001. Facilitating communication across lines of political difference: The role of mass media. American Political Science Review, 95(1), 97-114.

National NewsMedia Council. 2016. Decisions: 2016-33: Penna vs Toronto Star. Retrieved from: http://mediacouncil.ca/wp-content/uploads/2015/09/Penna-vs-Toronto-Star-decisionrelease.pdf.

Negroponte, N. 1996. Being digital. New York, NY, Vintage.

Netlytic. 2013. Netlytic. Retrieved from: http://netlytic.org/.

Newspaper Association of America. 2015. Newspaper digital audience springs forward to 176 million, boosted by mobile users. Retrieved from:

http://www.naa.org/ /media/NAACorp/Public\%20Files/TopicsAndTools/Digital/Mar2015Digita 1Audience.ashx.

Nguyen, A. 2008. Facing "the fabulous monster". The traditional media's fear-driven innovation culture in the development of online news. Journalism Studies, 9(1), 91-104.

Norton, A. and Leaman, J. 2004. The day after tomorrow: Public opinion on climate change. London, UK, MORI Social Research Institute.

Noveck, B. S. 2000. Paradoxical partners: Electronic communication and electronic democracy. Democratization, 7(1), 18-35

NPR. 2014, April, 1. Why doesn't America read anymore? NPR. Retrieved from: http://www.npr.org/2014/04/01/297690717/why-doesnt-america-read-anymore

Oeldorf-Hirsch, A. \& Sundar, S. 2015. Posting, commenting, and tagging: Effects of sharing news stories on Facebook. Computers in Human Behavior, 44, 240-249.

O'Neill, S., Boykoff, M. 2011. The role of new media in engaging individuals with climate change. In Whitmarsh, L., O'Neill, S.J. and Lorenzoni, I. (Eds.). Engaging the public with climate change: Communication and behaviour change (233-251). London, UK, Earthscan.

Palen, J. A. 1999. Objectivity as Independence Creating the Society of Environmental Journalists, 1989-1997. Science Communication, 21(2), 156-171.

Papacharissi, Z., \& de Fatima Oliveira, M. 2012. Affective news and networked publics: The rhythms of news storytelling on\# Egypt. Journal of Communication, 62(2), 266-282.

Pelham, B. W. 2009, April 22. Awareness, opinions about global warming vary worldwide. Gallup. Retrieved from: http://www.gallup.com/poll/117772/awareness-opinions-globalwarming-vary-worldwide.aspx. 
Pew Research Center. 2009. Public praises science; Scientists sault public, media. Retrieved from: http://www.people-press.org/2009/07/09/public-praises-science-scientists-fault-publicmedia/.

Pew Research Center. 2011. The state of news media: An annual report of American journalism. Retrieved from: http://www.stateofthemedia.org/overview-2011/.

Pew Research Center. 2014a. How social media is reshaping the news. Retrieved from: http://www.pewresearch.org/fact-tank/2014/09/24/how-social-media-is-reshaping-news/.

Pew Research Center. 2014b. Social networking fact sheet. Retrieved from: http://www.pewinternet.org/fact-sheets/social-networking-fact-sheet/.

Pew Research Center. 2015a. Digital news-audience: fact sheet. Retrieved from: http://www.journalism.org/2015/04/29/digital-news-audience-fact-sheet/.

Pew Research Center. 2015b. Newspapers: fact sheet. Retrieved from: http://www.journalism.org/2015/04/29/newspapers-fact-sheet/.

Pew Research Center. 2015c. State of the news media 2015. Retrieved from: http://www.journalism.org/2015/04/29/state-of-the-news-media-2015/.

Pew Research Center. 2015d. Cable news: Fact sheet. Retrieved from: http://www.journalism.org/2015/04/29/cable-news-fact-sheet/.

Pew Research Center. 2015e. The evolving role of news on Twitter and Facebook. Retrieved from: http://www.journalism.org/2015/07/14/the-evolving-role-of-news-on-twitter-andfacebook/.

Pew Research Center. 2016. What the world thinks about climate change in 7 charts. Retrieved from: http://www.pewresearch.org/fact-tank/2016/04/18/what-the-world-thinks-about-climatechange-in-7-charts/

Pierpoint, L. 2011. Fukushima, Facebook and feeds: Informing the public in a digital era. The Electricity Journal, 24(6), 53-58.

Posetti, J. 2009, June, 16. Twitter's difficult gift to journalism. New Matilda. Retrieved from: http://newmatilda.com/2009/06/16/twitters-difficult-gift-journalism.

Rice, M., Henderson-Sellers, A. \& Walkerden, G. 2015. Overcoming a diabolical challenge: Comparing journalists' and researchers' views on the performance of the media as a channel of climate information. International Journal of Science Education, 5(1), 1-22.

Richards J. \& Lewis P. 2011, December, 7. How Twitter was used to spread - and knock down rumours during the riots. The Guardian. Retrieved from:

https://www.theguardian.com/uk/2011/dec/07/how-twitter-spread-rumours-riots.

Riffe, D., Lacy S. \& Fico F.G. 2014. Analyzing media messages: Using quantitative content analysis in research. New York, NY, Routledge.

Scanfeld, D., Scanfeld, V. \& Larson, E. 2010. Dissemination of health information through social networks: Twitter and antibiotics. American Journal of Infection Control, 38(3), 182-188. 
Schäfer, S. M. 2012a. Hacktivism? Online media and social media as instruments of civil society's communication about climate change. Forschungsjournal Soziale Bewegungen, 25(2), $68-77$.

Schäfer, S.M. 2012b. Online communication on climate change and climate politics: A literature review. Wiley Interdisciplinary Reviews: Climate Change, 3(6), 527-543.

Schäfer, S. M. \& Sclichting I. 2014. Media representations of climate change: A meta-analysis of the research field. Environmental Communication, 8(2), 142-160.

Schonfeld, E. 2008, May, 22. ScribbleLive: Two guys in Canada launch sweet liveblogging platform. Tech Crunch. Retrieved from: http://techcrunch.com/2008/05/22/scribblelive-twoguys-in-canada-launch-sweet-liveblogging-platform/.

Scott, J. 1991. Social network analysis: A handbook. London, UK, SAGE Publications.

Scott, J. 2000. Social network analysis: A handbook. Thousand Oaks, CA, SAGE Publications.

Segerberg, A. \& Bennett, L. 2011. Social Media and the organization of collective action: Using Twitter to explore the ecologies of two climate change protests. The Communication Review, 14(3), 197-215.

SEJ. 2015. About SEJ. Retrieved from: http://www.sej.org/about-sej.

Shirky, C. 2011. The political power of social media: Technology, the public sphere, and political change. Foreign Affairs, 90, 28-41.

Shuckburgh, E., Robison, R. and Pidgeon, N. 2012. Climate science, the public and the news media. Cambridge, UK, Living with Environmental Change.

Stamm, R. K., Clark, F., \& Eblacas, R. P. 2000. Mass communication and public understanding of environmental problems: The case of global warming. Public Understanding of Science, 9, 219-237.

Stelter, B. 2009, June, 28. Journalism rules are bent in news coverage from Iran. New York

Times. Retrieved from:

http://www.nytimes.com/2009/06/29/business/media/29coverage.html?pagewanted=all.

Stephens, M. 2007. A history of news. New York, NY, Oxford University Press.

Stocking, H. \& Leonard, J.P. 1990. The greening of the media. Columbia Journalism Review, 29(4), 37-44.

Sullivan, J. \& Xie, L. 2009. Environmental activism, social networks and the internet. The China Quarterly, 198, 422-432.

Sun, S. 2011. Meta-analysis of Cohen's kappa. Health Services and Outcomes Research Methodology, 11(3-4), 145-163.

Sunstein, C. R. 2001. Republic.com. Princeton, NJ, Princeton University Press. 
Sustainable Development Solutions Network. 2015. Declaration of religious leaders, political leaders, business leaders, scientists and development practitioners. Pontificia Academia Scientiarvm, 1-5.

Szklarski, C. 2015, March, 26. CBC News, Radio-Canada job cuts will see 244 laid off. The Huffington Post. Retrieved from: http://www.huffingtonpost.ca/2015/03/26/cbc-news-lays-off144-sta_n_6949482.html.

Twitter. 2015a. Twitter usage/company facts. Retrieved from: https://about.twitter.com/company.

Twitter. 2015b. Twitter glossary. Retrieved from https://support.twitter.com/articles/166337-thetwitter-glossary.

Ungar, S. 1992. The rise and (relative) decline in global warming as a social problem. Sociological Quarterly, 33, 483-501.

Weber, E. U., \& Stern, P. C. 2011. Public understanding of climate change in the United States. American Psychologist, 66(4), 315.

White, B. 2013. Social media as a green virtual sphere: Examining the Alberta oil sands and the northern gateway pipeline on Twitter. (Unpublished master thesis) Dalhousie University, Nova Scotia.

White, D. M. 1950. The 'gatekeeper': a case study in the selection of news. Journalism Quarterly, 27, 383-390.

Whitmarsh, L. 2009. What's in a name? Commonalities and differences in public understanding of "climate change" and "global warming." Public Understand of Science, 18, 401-420.

Wilhelm, A. 1998. Virtual sounding boards: How deliberative is online political discussion. Information, Communication and Society, 1(3), 313-338.

Wimmer, R.D. \& Dominick, J.R. 1997. Mass media research: An introduction. Charlottesville, VA, Wadsworth Publishing.

Wyss, B. 2008. Covering the environment: How journalists work the green beat. Abingdon, UK, Routledge. 


\section{GLOSSARY}

Table 1 - Traditional and social media terms, definitions, and examples

\begin{tabular}{|c|c|c|}
\hline Term & Definition & Example \\
\hline Blog & $\begin{array}{l}\text { A website that contains regularly updated entries displayed } \\
\text { in reverse chronological order (Scanfeld et al., 2010). }\end{array}$ & $\begin{array}{l}\text { Huffington Post, Boing, Perezhilton, } \\
\text { Gawker }\end{array}$ \\
\hline Degree Centrality & $\begin{array}{l}\text { The number of connections a user has with other users. } \\
\text { These include retweets, mentions, and replies. }\end{array}$ & N/A \\
\hline Liveblog & $\begin{array}{l}\text { A minute-by-minute Blog post used by news organizations } \\
\text { to provide continuous and instantaneous coverage of a } \\
\text { breaking or special event. Software platforms are available } \\
\text { to create Liveblogs on News Websites (Schonfeld, 2008). }\end{array}$ & Software platforms: ScribbleLive \\
\hline Microblog & $\begin{array}{l}\text { A form of blogging that allows users to send brief text } \\
\text { updates or micromedia to be viewed by the public or a } \\
\text { restricted group (Scanfeld et al., 2010). }\end{array}$ & $\begin{array}{l}\text { Twitter, Facebook (see Newsfeed in } \\
\text { Table 2), Tumblr }\end{array}$ \\
\hline $\begin{array}{l}\text { News Website } \\
\text { (Digital News) }\end{array}$ & $\begin{array}{l}\text { The online version of news organizations such } \\
\text { as newspapers, television broadcasters/stations, radio } \\
\text { broadcasters/stations, news agencies, or online-only news } \\
\text { resources. }\end{array}$ & $\begin{array}{l}\text { nytimes.com, cnn.com, bbc.com, } \\
\text { cbc.ca, reuters.com, } \\
\text { huffingtonpost.com }\end{array}$ \\
\hline $\begin{array}{l}\text { Photo/Video } \\
\text { Sharing }\end{array}$ & $\begin{array}{l}\text { A website that enables the publishing of digital photos or } \\
\text { video clips online, facilitating sharing with others } \\
\text { (Scanfeld et al., 2010). }\end{array}$ & $\begin{array}{l}\text { Youtube, Flickr, Tumblr, Facebook, } \\
\text { Twitter } \\
\text { Note: Many social networking sites } \\
\text { support multimedia (a combination of } \\
\text { text, audio, photos, video, animation, } \\
\text { links, and interactive components) }\end{array}$ \\
\hline $\begin{array}{l}\text { Social Media (See } \\
\text { Social Network) }\end{array}$ & $\begin{array}{l}\text { Social media are tools that allow users to create or } \\
\text { exchange information, opinions, and pictures/videos in } \\
\text { virtual communities. Social media builds on the } \\
\text { ideological and technological foundations of Web } 2.0 \\
\text { (Kaplan \& Haenlein, 2010). }\end{array}$ & Facebook, Twitter, Youtube \\
\hline $\begin{array}{l}\text { Social Network } \\
\text { (See Social Media) }\end{array}$ & $\begin{array}{l}\text { Online community where a user can create a profile and } \\
\text { build a personal network that connects him or her to other } \\
\text { users (Scanfeld et al., 2010). }\end{array}$ & $\begin{array}{l}\text { Facebook, Twitter (see microblog), } \\
\text { Myspace, Google+, Youtube (see } \\
\text { photo/video sharing) }\end{array}$ \\
\hline $\begin{array}{l}\text { Social News } \\
\text { Pathway }\end{array}$ & $\begin{array}{l}\text { A Social Network used to access/share news from News } \\
\text { Websites. }\end{array}$ & Facebook, Youtube, Twitter \\
\hline Traditional Media & $\begin{array}{l}\text { Means of communication that have existed since before the } \\
\text { Internet. Industries that are considered part of traditional } \\
\text { media and are discussed in this paper include newspaper, } \\
\text { radio, and television. Many traditional media outlets now } \\
\text { have digital versions of their publications/broadcasts, these } \\
\text { are referred to as News Websites or Digital News. News } \\
\text { Websites are still considered traditional media as they are } \\
\text { not interactive and the content is generated by } \\
\text { professionals while social media is interactive and the } \\
\text { content is produced by anyone. } \\
\text { Note: This research will focus on content generated by the } \\
\text { top nine American digital news entities (traditional media) } \\
\text { that is shared on either Facebook or Twitter (social media) } \\
\text { with a link. }\end{array}$ & $\begin{array}{l}\text { The New York Times, CNN, BBC, } \\
\text { Fox News, National Geographic }\end{array}$ \\
\hline Web 2.0 & $\begin{array}{l}\text { The social use of the Web which allow people to } \\
\text { collaborate, to get actively involved in creating content, to } \\
\text { generate knowledge and to share information online } \\
\text { (Grosseck, 2009). }\end{array}$ & $\begin{array}{l}\text { Huffington Post, a comment section } \\
\text { on any news website, Twitter, Reddit }\end{array}$ \\
\hline
\end{tabular}


Table 2 - Twitter-related terms and definitions

\begin{tabular}{|l|l|l|}
\hline $\begin{array}{l}\text { Social } \\
\text { Network }\end{array}$ & Term & Definition \\
\hline \multirow{4}{*}{ Twitter } & Favorite & $\begin{array}{l}\text { Favoriting a tweet can signal to the original poster that someone liked their } \\
\text { tweet. Favoriting can also save a tweet for later. }\end{array}$ \\
\cline { 2 - 3 } & Follow & $\begin{array}{l}\text { Following is used to subscribe to a user's updates. When someone posts a } \\
\text { new message, it appears in his/ her followers' Twitter home page in real } \\
\text { time. }\end{array}$ \\
\cline { 2 - 3 } & Hashtag & $\begin{array}{l}\text { Hashtags, created by prefixing a word with '\#', are included in tweets to } \\
\text { mark them as relating to a topic, this groups specific subjects so that people } \\
\text { can follow the conversation. }\end{array}$ \\
\cline { 2 - 3 } $\begin{array}{l}\text { * Twitter } \\
\text { terms } \\
\text { retrieved } \\
\text { from } \\
\begin{array}{l}\text { Twitter } \\
\text { Glossary } \\
\text { (Twitter, } \\
\text { 2015b) }\end{array}\end{array}$ & RT (Retweet) & $\begin{array}{l}\text { A Retweet is a re-posting of someone else's tweet. “RT" is included in a } \\
\text { tweet to indicate that it contains text from another person's tweet, optionally } \\
\text { adding additional content. }\end{array}$ \\
\cline { 2 - 3 } & Trending & $\begin{array}{l}\text { Trends identify topics that are popular at the moment. These are determined } \\
\text { by an algorithm and are tailored based on who a user follows and his/her } \\
\text { location. }\end{array}$ \\
\cline { 2 - 3 } & Tweet & A Twitter update/post. A tweet can include text, photos, videos, and/or links. \\
\hline
\end{tabular}

